Baskın, S. ve Toyran, M. (2021). Yurt dışında yaşayan Türkler ve Türkçe eğitimi: İngiltere örneği (Genel durum, sorunlar ve öneriler). Ana Dili Eğitimi Dergisi, 9(4), 1128-1150.

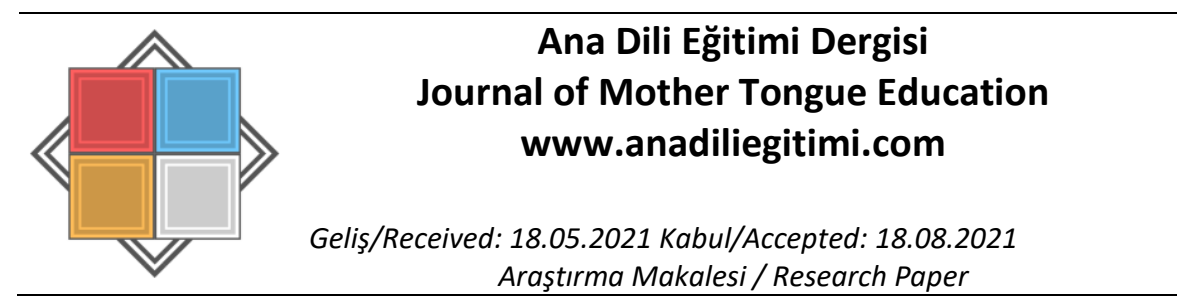

\title{
Yurt Dışında Yaşayan Türkler ve Türkçe Eğitimi: İngiltere Örneği (Genel Durum, Sorunlar ve Öneriler)
}

\author{
Sami BASKIN* \\ Mehmet TOYRAN**
}

\begin{abstract}
Öz
Ingiltere'ye çeşitli zamanlarda yerleşmiş yarım milyondan fazla Türk bulunmaktadır. Bu Türkler, dil ve kültürlerini korumak için faaliyetler yürütmektedir. Bunlardan birisi de çocuklarına Türkçe ve Türk Kültürü dersini aldırmaktır. İngiltere'de Türkçe ve Türk Kültürü dersi, Türkiye'den ve Kuzey Kıbrıs Türk Cumhuriyeti'nden (KKTC) gelen öğretmenler tarafından verilmektedir. 2020-2021 eğitim-öğretim yılı itibarıyla $38^{\prime} i$ Türkiye'den, $11^{\prime} i$ KKTC'den olmak üzere toplam 49 öğretmen tarafından bu ders verilmektedir. Bu çalışmada Türkçe ve Türk Kültürü dersinin İngiltere'de nasıl, nerede, hangi şartlarda verildiğini ortaya koymak amaçlanmıştır. Bu çalışmada Türkçe ve Türk Kültürü dersi bir fenomen olarak düşünülmüş ve fenomenolojik bir araştırma tasarlanmıştır. Türkiye Cumhuriyeti Londra Eğitim Müşavirliğine bağlı olarak görev yapan 10 öğretmenle bir odak grup görüşmesi gerçekleştirilmiş ve beş farklı konuda (ders ortamları, öğretmenler, öğrenciler, veliler, ders araç-gereçleri) onların görüşleri alınmıştır. Yapılan görüşsmenin kayıtları analiz edilmiş ve bir bütünlük arz edecek şekilde düzenlenmiştir. Araştırma sonuçlarına göre, İngiltere'de Türkçe ve Türk Kültürü dersi için tahsis edilmiş belirli bir yer olmadığı; cami, halk eğitim merkezi veya resmi okullarda tahsil edilen odalarda eğitimin yapıldığı; her branştan öğretmenlerin bu ders için görevlendirildiği; ders araç gereçlerinin genellikle öğretmenler tarafından hazırlandığı; ulusal sınavlara Türkçe dersinden girenlerin derse daha fazla ilgi gösterdiği; velilerin ders açılması için çaba gösterdiği ancak ders açıldıktan sonra öğrenme ortamıyla çok fazla ilgilenmedikleri tespit edilmiştir.
\end{abstract}

Anahtar Kelimeler: Türkçe ve Türk Kültürü dersi, İngiltere, ana dili eğitimi

\section{Turks Living Abroad and Turkish Education: The Case of England (State of Affairs, Problems, and Suggestions)}

\begin{abstract}
More than half a million Turks live in England. They carry out many activities to preserve their language and culture. One of them is to ensure that their children attend the Turkish and Turkish Culture course. Turkish and Turkish Culture course is taught by teachers from Turkey and the Turkish Republic of Northern Cyprus (TRNC). In the 2020-2021 academic year, the course was taught by a total of 49 teachers, 38 from Turkey and 11 from TRNC. The goal of this study is to find out how, where, and under what conditions the Turkish and Turkish Culture course is taught in England. The phenomenological research design was used in the study. A focus group meeting was held with 10 teachers to capture their opinions on five different areas, namely, teaching environments, teachers, students, parents, and course materials. The results showed that there was no location allocated for teaching the Turkish and Turkish Culture course in England. The course was taught in temporarily reserved rooms at mosques, public education centers, or public
\end{abstract}

\footnotetext{
${ }^{*}$ Doç. Dr., Tokat Gaziosmanpaşa Üniversitesi, Eğitim Fakültesi, Türkçe ve Sosyal Bilimler Eğitimi Bölümü, Tokat, samibaskin@gmail.com, ORCID: orcid.org/0000-0002-4159-5480

** Dr., Beyoğlu İlçe Milli Eğitim Müdürlüğü Şube Müdürü, ìstanbul, toyran1@gmail.com, ORCID: orcid.org/00000001-5685-592X
} 
schools. Teachers from all subject areas were assigned to teach the course. Teachers generally prepared the teaching materials. The results showed that students who chose Turkish as a subject in the national exams were more interested in the course. Parents also made an effort for the course to be offered, but they did not pay much attention to the learning environments once the course was offered.

Keywords: Turkish and Turkish Culture course, England, mother tongue education

\section{İngiltere'deki Türkler}

\section{Giriş}

Daha önceleri savaşlar, yaşam koşulları, siyasi ve sosyal olaylar zorunlu göçlere sebep olurdu. Günümüzde ise bu sebeplerin yanına teknolojinin gelişimi, ulaşımın kolaylaşması ve iş olanaklarının çeşitlenmesi gibi pek çok ekten daha eklenmiştir. Ayrıca bu yeni faktörler hem göç etmeyi kolaylaştırmakta hem de teşvik etmektedir. Bu yüzden dünya çapında büyük bir nüfus hareketliliği mevcuttur ve her milletten bireyleri dünyanın hemen her yerinde görmek mümkündür. Türkiye Cumhuriyeti Dışişleri Bakanlığı verilerine göre hâlihazırda yurt dışında 6,5 milyonu aşkın Türk vatandaşı yaşamaktadır. Bunların yaklaşık 5,5 milyonu Batı Avrupa ülkelerindedir. Türkiye'ye kesin dönüş yapmış olan 3 milyon kişi de düşünüldüğünde yaklaşık 9,5 milyonluk bir kitleyi ilgilendiren, geniş kapsamlı bir göç olgusunun varlığı ortaya çıkmaktadır (T.C. Dışişleri Bakanlığı, 14.05.2021). Türklerin Batı Avrupa ülkelerine yoğun bir şekilde yerleşmiş olmalarının birinci nedeni Türkiye Cumhuriyeti'nin Avrupa Birliği ülkeleri ile yapmış olduğu anlaşmalardır. Örneğin 1961 yılında önce Almanya ile ve daha sonraki yıllarda ise diğer Batı Avrupa ve İskandinav ülkeleri ile imzalanan misafir işçi anlaşmaları kapsamında yapılan göçler, kısa sürede yüzbinlerce Türk'ün bu ülkelere taşınmasına neden olmuştur (Kaya, 2008: 151). Bu anlaşmalar (örneğin Ankara Anlaşması, 1963) Türk vatandaşlarına genel geçer bir sermaye ve dil şartı olmaksızın $A B$ ülkelerinde çalışma olanağı vermiştir. Olanakları değerlendiren Türkler, pek çok ülkeye gitmiş olsalar da en çok Almanya, Avusturya, Belçika, Fransa ve İngiltere'yi tercih etmişlerdir. Söz gelimi 2017 yılında İngiltere İçişleri Bakanlığı tarafından yapılan açıklamaya göre Birleşik Krallık'ta yaşayan Türk sayısı 850 bindir. Sadece Londra'da yaşayan Türk sayısı 450 bin civarındadır (ICEPWORLD, 2017). Bu sayıya Kuzey Kıbrıs Türk Cumhuriyeti'nden (KKTC) ve diğer bölgelerden göçen Türkler de dâhildir. Ancak Birleşik Krallık'ta yaşayan Türkler arasında en kalabalık grubu Türkiye'den gidenler oluşturmaktadır.

İngiltere'ye KKTC'den gelen Türklerin adadaki geçmişi Türkiye'den gelenlerden farklıdır. Büyük Britanya Imparatorluğu'nun 1878 yılında Kıbrıs Adası'nı Osmanlı İmparatorluğu'ndan kiralaması sonucunda, Kıbrıs'ta yaşayanlara "Ingiliz tabiiyeti" (British subject) verilmiştir. Bu gelişme, Kıbrıs vatandaşlarına yeni imkânlar doğurmuştur. Bu yüzden adaya önemli sayıda Kıbrıs Türk'ü göçmüştür. Yine I. Dünya Savaşı, II. Dünya Savaşı ve Kıbrıs'taki diğer siyasi ve sosyal olaylar İngiltere'ye göçü tetiklemiştir. Ama Birleşik Krallık'a en yoğun göçün 1960 yılından sonra yaşandığı (KKTC Dışişleri Bakanlığı, 14.05.2021), günümüzde Kıbrıs doğumlu olanların 150 bin civarında olduğu bilinmektedir (Wikipedia, 02.01.2021).

Sayıları Kıbrıslı Türkler ve Türkiyeli Türkler kadar olmasa da Bulgaristan, Yunanistan, Makedonya, Romanya gibi Balkan ülkelerindeki Türklerden, Azerbaycan'dan, Irak ve Suriye Türkmenlerinden İngiltere'ye göçler yaşanmıştır (Uysal, 2016a: 544). Bu Türkler, daha çok 1960'lardan sonra işçi olarak Ingiltere'ye gelmiştir. Daha sonra aile kurma, eğitim yoluyla buraya gelenlerin sayısı artmıştır. Özellikle Yunanistan'ın ve Bulgaristan'ın AB üyesi olmasıyla bu ülkelerden İngiltere'ye gelmek kolaylaşmıştır. Bu da söz konusu bölgelerden adaya göçü arttırmıştır.

Çeşitli yerlerden, farklı sebeplerle İngiltere'ye gelen Türkler, çoğunlukla başkent Londra'da yaşamaktadır. 2017 yııı itibarıyla yapılan değerlendirmelere göre Londra'da 400 - 450 bin civarında Türk yaşamaktadır. Özellikle Kuzey Londra'da yoğun bir Türk nüfusu vardır (Wikipedia, 02.01.2021). İngiltere bu yönüyle diğer Avrupa ülkelerinden ayrılır. Diğer Avrupa ülkelerinde nüfus ülke içinde farklı şehirlere dağılmış olmasına rağmen İngiltere'de bir şehirde ve o şehrin bir kesiminde yoğunlaşmıştır. Bazı kaynaklara göre İngiltere'deki Türklerin \%75'i (Uysal, 2016a: 549), bazılarına göre de \%90'ı (Demir, 2016) Londra'da yaşamaktadır. Bu tespitler yakın zamana kadar doğru olsa da son yıllarda İngiltere'ye yerleşen Türk sayısında büyük bir artış gözlemlenmiştir. Yeni gelen Türkler, Kuzey Londra'nın yanı sıra, 
Londra'nın güneybatısında yer alan Fulham, Richmond ve Wimbledon gibi görece daha konforlu kesimleri tercih etmektedir.

Türklerin adadaki sayılarının artmasıyla birlikte sorunları, uğraş alanları, ihtiyaçları artmıştır. Bütün bunları aşabilmek için dernek, kulüp, vakıf gibi çeşitli sivil toplum kuruluşları kurmuşlardır. Uysal (2016b), Londra'da var olan 100 civarındaki sosyo-kültürel organizasyonu ait oldukları çatı örgütü esas alarak dört başlık altında anlatmıştır. Buna göre günümüzde Londra'da Türkler şu çatı örgütlere sahiptir:

- İngiltere Kıbrıs Türk Dernekleri Konseyi

- İngiltere Türk Dernekleri Federasyonu

- Demokratik Güç Birliği Platformu

- Bir Çatı Kuruluş Altında Olmayan Organizasyonlar

Ingiltere'de yaşayan Türkler genellikle tekstil ve gıda sektöründe faaliyet göstermektedir. Bunun yanında öğrenci veya görevli olarak bu ülkeye geçici olarak yerleşmiş çok sayıda Türk vardır (ICEPWORLD, 2017). Onların yaşadığı bölgelerde Simit Sarayı, Kahve Dünyası, Korkmaz Market, Altın Makas gibi Türkiye'nin hemen her şehrinde rastlanılan işletmeler bulunmaktadır. Bu da adaya göçen Türklerin alışkanlıklarını, geleneklerini burada da sürdürdüklerini göstermektedir. Türkiye Cumhuriyeti bu ögelerin ve kültürel bağların devamlılı̆ını koruyup genişletebilmek; Türk toplumu mensuplarının ana dilleri ve kültürleri ile bağlarını sonraki kuşaklara aktarabilmek, bulundukları toplumların sosyal, ekonomik, siyasal ve kültürel hayatına katkıda bulunmalarını sağlamak, onların hukuk düzenine saygılı, mutlu ve refah içinde yaşamalarını temin etmek için büyük bir çaba sarf etmektedir (T.C. Dışişleri Bakanlığı, 14.05.2021). Bu çabalardan biri de İngiltere'ye öğretmenler göndererek yeni kuşakların Türkçe ve Türk kültürünü öğrenmelerini sağlamaktır.

\section{Yurt Dışında Türkçenin Eğitimi}

Ana dili "ilk önce anneden, daha sonraları ise aşama aşama ailenin diğer fertleri, yakın çevre ve çocuğun içerisinde bulunduğu ortamda kavradığı; bilinçaltına inen ve bireylerin toplumla en güçlü bağlarını oluşturan dil” olarak tanımlanmaktadır (Aksan, 1975, s. 427). Bireyin sesleri anlaması, anlamlandırması aile bireylerini taklit yoluyla mümkün olabilmektedir. Ilerleyen yıllarda bu becerisi bireyin çevresiyle gelişir, zenginleşir. Okul çağına kadar aile ve çevreyle işlenen ana dilinin sistematik biçimde geliştirilmesi ise eğitim kurumları aracılığıyla mümkün olmaktadır.

Bireyin içine doğduğu toplumla ve öz kültürüyle güçlü bir bağ kurmasını sağlayan ana dili eğitiminin gerçekleştirilmesi T.C. Millî Eğitim Bakanlığının (MEB) temel amaçlarından birisidir. 1739 sayılı Millî Eğitim Temel Kanununda; "Türk vatandaşlarının ve Türk toplumunun refah ve mutluluğunu artırmak; öte yandan milli birlik ve bütünlük içinde iktisadi, sosyal ve kültürel kalkınmayı desteklemek ve hızlandırmak ve nihayet Türk Milletini çağdaş uygarlığın yapıcı, yaratıcı, seçkin bir ortağı yapmaktır." ifadeleri bulunmaktadır. Bu kanunda hedeflenen amaçlara ulaşmak için Millî Eğitim Bakanlığı hem yurt içinde hem de yurt dışında yaşayan vatandaşlar için çeşitli programlar düzenlemektedir.

Ana dili eğitimi Türkiye'de resmî ve özel okullar aracılığıyla gerçekleşmektedir. Türkçe, edebiyat veya Türk dili dersleri ile okul öncesinden üniversiteye kadar kesintisiz bir şekilde devam eden bu eğitim ile bireylerin;

- dinleme/izleme, konuşma, okuma ve yazma becerilerinin geliştirilmesi,

- Türkçeyi, konuşma ve yazma kurallarına uygun olarak bilinçli, doğru ve özenli kullanmalarının sağlanması,

- okuduğu, dinlediği/izlediğinden hareketle, söz varlığını zenginleştirerek dil zevki ve bilincine ulaşmalarının; duygu, düşünce ve hayal dünyalarını geliştirmelerinin sağlanması,

- okuma yazma sevgisi ve alışkanlığını kazanmalarının sağlanması,

- duygu ve düşünceleri ile bir konudaki görüşlerini veya tezini sözlü ve yazılı olarak etkili ve anlaşılır biçimde ifade etmelerinin sağlanması,

- bilgiyi araştırma, keşfetme, yorumlama ve zihinde yapılandırma becerilerinin geliştirilmesi,

- basılı materyaller ile çoklu medya kaynaklarından bilgiye erişme, bilgiyi düzenleme, sorgulama, kullanma ve üretme becerilerinin geliştirilmesi, 
- okuduklarını anlayarak eleştirel bir bakış açısıyla değerlendirmelerinin ve sorgulamalarının sağlanması,

- millî, manevi, ahlaki, tarihî, kültürel, sosyal değerlere önem vermelerinin sağlanması, millî duygu ve düşüncelerinin güçlendirilmesi,

- Türk ve dünya kültür ve sanatına ait eserler aracılığıyla estetik ve sanatsal değerleri fark etmelerinin ve benimsemelerinin sağlanması amaçlanmaktadır (Türkçe Öğretim Programı, 2019: 8).

Millî Eğitim Bakanlığı bu amaç ve hedeflerini sadece yurt içinde değil, Türklerin yaşadığı her yerde gerçekleştirmek istemektedir. Bunun için Türkiye Cumhuriyeti Bakanlıklararası Ortak Kültür Komisyonunun (BAOKK) onayı ile yurt dışına Türkçe ve Türk Kültürü öğretmenleri gönderilmektedir. 2003'te imzalanan Bakanlıklararası Ortak Kültür Komisyonunun Çalışma Esas ve Usulleri ile Bu Komisyon Tarafından Yurtdışında Görevlendirilecek Personelin Nitelikleri ile Hak ve Yükümlülüklerinin Belirlenmesine İlişkin Karar'da yer alan “Türk kültürünün yurt dışında tanıtılması, yayılması ve korunması, yurt dışındaki vatandaşlarımız ve soydaşlarımızın kültürel bağlarının korunması, güçlendirilmesi ve dini konularda aydınlatılması ile Türk dilinin öğretilmesi" maddesi (1. madde) Millî Eğitim Bakanlığının amacını somut bir biçimde ifade etmektedir. Bu madde aynı zamanda yurt dışındaki vatandaşlara yönelik din, kültür ve eğitim faaliyetlerine de yasal dayanak oluşturmaktadır.

Millî Eğitim Bakanlığı Yükseköğretim ve Yurt Dışı Eğitim Genel Müdürlüğü (YYEGM) organizasyonuyla yürütülen en önemli eğitim faaliyeti yurt dışında yaşayan Türklerin Türkçe ve Türk Kültürü dersleri aracılığıyla kendi dillerini ve kültürlerini öğrenmelerini sağlamaktır. Bakanlık bu ders için; Türkçe, Türk Dili ve Edebiyatı, İngilizce, Sınıf Öğretmenliği, Din Kültürü ve Ahlak Bilgisi gibi çeşitli branşlardan öğretmenler görevlendirmektedir. Bu kapsamda 2020-2021 eğitim öğretim yılı için 37 ülkede 1610 Türkçe ve Türk Kültürü öğretmeni görevlendirilmiştir (YYEGM). Bu öğretmenler gittikleri yerlerin devlet okullarında, Türk dernek okullarında veya Maarif Vakfına bağlı olarak açılan okullarda çalışmaktadır.

\section{Ingiltere'de Ana Dili Olarak Türkçenin Eğitimi}

Türkçe, İngiltere'de en çok konuşulan on dilden birisidir (Mapping London, 2013). Özellikle Londra'da önemli sayıda Türk yaşamaktadır ve şehrin bazı bölgelerinde Türkçe günlük hayatta sıklıkla kullanılan bir dildir. Bu Türk nüfusunun Türkçe ve Türk kültürü ile bağlarının devam ettirilmesi ve kendi ana dilleri ile kültürlerini unutmamalarının sağlanması için ana dili eğitimi oldukça önemlidir. Bunun sağlanması için T.C. Millî Eğitim Bakanlığı, İngiltere'de yaşayan Türk çocuklarının ülkenin resmî eğitim kurumlarına devam ederken eş zamanlı olarak Türkçe eğitimini alabilmeleri için adaya öğretmenler görevlendirmiştir. Hafta içi İngiliz okullarında eğitim gören Türk çocukları akşamları ya da hafta sonları Türk okullarına gidebilmektedir. Ancak bu okullar, alışılagelmiş okul modelinden bariz biçimde farklıdır. Bayat (2016) bu okulları merkez olarak adlandırmış ve klasik okul kavramı dışında tutmuştur. Çünkü bu okullar, Türkçe ve Türk kültürünün öğretildiği, haftanın sadece bir veya birkaç günü, 2-4 saat eğitimöğretimin yapıldığı yerlerdir. Bu nedenle söz konusu okullar işlevsel açıdan kurs gibidir; fakat yüklendikleri misyon açısından okuldurlar. Gönüllü iştirakler olarak ortaya çıkan Türk Dernek Okullarını devlet kurumları da yalnız bırakmamıştır. Okulların öğretmen ihtiyacı Türkiye Cumhuriyeti Londra Eğitim Müşavirliği, KKTC Eğitim ve Kültür Ataşeliği tarafından görevlendirilen öğretmenler ile gönüllü öğretmenler tarafından karşılanmaktadır. Bu iki kurumun daha organize eğitim verebilmesini sağlamak ve İngiltere'deki kurumlarla resmî bağlantılar yapabilmek amacıyla da 2013 yılında İngiltere Türk Dili, Kültürü ve Eğitim Konsorsiyumu kurulmuştur. Ingiltere'de ana dili olarak Türkçe eğitiminin hem personel hem de eğitim materyali açısından yükü ise daha çok Londra Eğitim Müşavirliğindedir.

Ingiltere'de 2020-2021 eğitim-öğretim yılı itibarıyla T.C. Londra Eğitim Müşavirliğine bağı olarak 5'i Türkçe öğretmeni, 7'si Türk dili ve edebiyatı öğretmeni, 9'u sınıf öğretmeni, 8'i İngilizce öğretmeni, 4'ü din kültürü ve ahlak bilgisi öğretmeni, 2'si muhasebe öğretmeni, 1'i sosyal bilgiler öğretmeni, 1'i matematik öğretmeni, 1'i de rehber öğretmen olmak üzere toplam 38 öğretmen görev yapmaktadır. Bu dağılımdan da anlaşılacağı üzere Millî Eğitim Bakanlığı, Türkçe ve Türk Kültürü derslerini yürütmek üzere öğretmen görevlendirirken branş ayrımı yapmamaktadır. Tüm öğretmenler branşlarına bakılmaksızın Türkçe ve Türk Kültürü öğretmeni adıyla görev yapmaktadır. İngiltere'de öğretmenler; $1,2,3,4,5,6,7$, 8. seviye Türkçe ve Türk Kültürü derslerinin yanı sıra İngiliz eğitim 
sistemindeki lise bitirme sınavı olan GCSE Turkish (General Certificate of Secondary Education) ve üniversiteye giriş sınavı olan ve A Level Turkish (Advanced Level) sınavlarının hazırlı̆ını da üstlenmektedir. Bu görev dağııımında da branşlara veya uzmanlıklara bakılmamaktadır. Yurt dışında bir seferde istisnalar hariç en fazla 5 yıl kalabilen öğretmenler, her sene başında yeni bir görevlendirme ile sınıflarının başına geçmektedir. Bu sınıflar bilinen sınıf düzeninden oldukça farklıdır. Bunlar, Türkiye'deki eğitim ile kıyaslanacak olursa birleştirilmiş sınıflara benzetilebilirler.

İngiltere'de Türkçe ve Türk Kültürü dersleri, ülkede var olan camiler, sosyal örgütlenmeler (dernekler, vakıflar) vb. aracılığıyla bir araya gelen velilerin çocuklarına kendi dil ve kültürlerini öğretmek için T.C. Londra Eğitim Müşavirliği veya KKTC Eğitim Ataşeliğinden öğretmen talepleri üzerine gerçekleşmektedir. Müşavirlik ve ataşelikten öğretmen talep edenler; cami, dernek, kültür merkezi veya herhangi bir okulun bir bölümünü eğitim-öğretime hazırlamaktadır. Bu yüzden eğitimin verildiği ortamlar, öğretmenler ya da öğrenciler sürekli değişebilmektedir. Durum böyle olduğundan ders için bir araya gelen öğrencilerin sayısı 3 ila 20 arasında değişebilmektedir. Bu öğrencilerin arasında hem yaş hem de seviye farklııkları da bulunabilmektedir. Bazen öğrencilerin yaşı 5 ile 18 arasında değişirken Türkçe bilgi seviyeleri de 1-8 arasında değişebilmektedir. 8. seviyeden sonra GCSE Turkish ve A Level Turkish adı verilen sınavlara hazırlanabilmektedirler. Öğrenci seviyeleri, okul yönetimlerinin ve ders öğretmeninin gözlem ve değerlendirmesi sonucunda belirlenmektedir. Ders materyalleri öğrencilerin seviyelerine göre dağıtılırken öğrenme yöntem ve teknikleri öğretmenin hünerine kalmaktadır. Ayrıca bu öğrenciler seviyelendirilmiş sınıflarda değil, diğer sevilerdeki öğrencilerle aynı ortamda eğitim almaktadır.

Ingiltere'de ana dili olarak Türkçe eğitimi dersleri, 2021 yılı itibarıyla büyük bir kısmı Londra'da olmak üzere $45^{\prime} i$ İngiliz okullarında, $49^{\prime}$ u ise Türk dernek okullarında (cami, kültür merkezi vb.) devam etmektedir. Bu okullarda "ders genellikle birleştirilmiş sınıf düzeninde gerçekleşir. Öğrenci çeşitliliği ve birleştirilmiş sınıf düzeni, farklı öğretim yöntem ve tekniklerini bir arada ve dengeli bir şekilde kullanmayı gerektirir. İşbirlikli öğrenme, grup çalışmaları, bireyselleştirilmiş öğretim, ilgi ve seviye grupları vb. uygulamalarla öğrencilerin derse aktif katıımı sağlanmalıdır" (MEB, 2018). Bu yüzden öğretmenler uzun bir hazırlık süreci ve büyük bir öğretme gayreti ile Türkçe ve Türk Kültürü dersini icra etmektedir.

"Türkçe ve Türk Kültürü dersinin amacı yurt dışındaki Türk çocuklarının Türkçeyi etkili bir şekilde edinmesini sağlamak ve onların Türkçe dinleme, konuşma, okuma ve yazma becerilerini geliştirmektir. Ana dili Türkçeyi daha etkin kullanmanın yanı sıra yurt dışında yaşayan Türk çocuklarına Türk kültürünün temel unsurlarını aktarmak, Türk kültürü ile bulundukları ülkenin kültürel ögelerini ilişkilendirerek kültürlerarasılık özelliklerini geliştirmek dersin bir diğer amacıdı" (MEB, 2018: 3). Programda belirtilen bu amaçların gerçekleşebilmesi için eğitim-öğretimin sekiz farklı seviyede yapılması öngörülmüştür. Bu seviyelere uygun olarak hazırlanan ve içerisinde Ben ve Ailem, Çevre, Farklılıklar ve Birlikte Yaşama, Oyun ve Eğlence, Bayramlar ve Kutlamalar, Gezelim Görelim, Geçmişe Açılan Kapı, Sanat ve Edebiyat, İnsan ve Doğa temaları bulunan Türkçe ve Türk Kültürü ders kitapları 2019-2020 yılından itibaren öğrencilere ücretsiz olarak dağıtılması kararlaştırılmıştır. Derslerde bu kitaplarının yanı sıra eğitim içerikli sitelerden alınan materyaller veya öğretmenlerin hazırladıkları özgün materyaller kullanılmaktadır. Nitekim İngiltere'de görevli öğretmenler tarafından 2018 yılında Türkçe ve Türk Kültürü Ders Materyalleri kitabı hazırlanmış (Çalışkan ve Toyran, 2018) ve öğrencilere dağıtılmıştır.

Görüldüğü üzere Türkçenin ana dili olarak eğitimi sadece Türkiye'de gerçekleşmemektedir. Türklerin yoğun yaşadığı yerlerde Türkçe ve Türk Kültürü dersi vasıtasıyla Türkçe eğitimi yapılmakta, Türkçenin ve Türk kültürünün devamlılığı sağlanmaktadır. Ancak bunlar ile ilgili araştırma sayısı oldukça sınırlıdır. Bu çalışma, ilgili literatüre bir katkı sunması ve yurt dışında yapılan Türkçe eğitiminin, İngiltere özelinde nasıl gerçekleştiğini göstermesi bakımından önemlidir. Çalışmada söz konusu eğitimin ortamı, paydaşları ve süreci betimlenmektir. Bunun için araştırma "Ingiltere'de Türkçe ve Türk kültürü eğitimi nasıl gerçekleşiyor?" problem cümlesi üzerine inşa edilmiştir. Bu problem cümlesini somutlaştırabilmek için eğitimin paydaşları olan okullar, ders materyalleri, veliler ve öğretmenler ile ilgili sorular da sorulmuştur. Bu soruların her biri birer alt problem olarak ele alınmış ve tümevarım yöntemi ile birleştirilerek bir sonuca varılmıştır. 


\section{Araştırmanın Modeli}

\section{Yöntem}

Araştırmanın modeli, fenomenolojidir. Fenomenolojik araştırmalar, bir durumu tanımlamaya ve açıklamaya yönelik olarak düzenlenebilir. Burada İngiltere'de gerçekleşen Türkçe ve Türk Kültürü dersi bağlamında Türkçe eğitiminin tanımlanması ve açıklanması hedeflenmiştir.

Fenomenolojinin ana varsayımı yalnızca deneyimlerle yaşananların bilinebileceğidir. Bu deneyimler eleştirel biçimde ve ayrıntılı olarak analiz edildiğinde olguların özüne ilişkin genel bir anlayış oluşacaktır (Şimşek, 2018: 97). Bu araştırmalarda araştırılacak "fenomene" vurgu yapılarak katılımcıların bu fenomene ilişkin algıları ve bakış açıları, bu fenomeni nasıl anlamlandırdıkları, fenomeni nasıl deneyimledikleri ve bu deneyimlerini nasıl betimledikleri üzerine odaklanılmaktadır. Odaklanılan bu fenomen bir kavram, bir düşünce ya da bir duygu olabilmektedir (Tekindal ve Uğuz Arsu, 2020: 158). Bireylerin bakış açılarından deneyimleri genellikle görüşmeler, tartışmalar, katılımcı gözlem ve katılımcılar bakış açısından yansıtma gibi nitel yöntemler kullanılarak toplanır. Böylece derinlemesine bilgi edinilmiş ve tümevarımcı algılar derlenmiş olur (Kuzu, 2013: 35). Bu araştırmada temel fenomen olan Türkçe ve Türk Kültürü dersine ait öğretmen deneyimleri bir nitel veri toplama aracı olan odak grup görüşmesi ile toplanmıştır.

\section{Araştırma grubu}

Genellikle, araştırmacılar bir fenomenin farklı ortamlarda (şehir, kasaba ve kırsal alanda), farkı zamanlarda (eğitim-öğretim dönemleri içinde, yaz okulu süresince vb.) ve farklı insanlar (öğretmenler, doktorlar, çiftçiler vb.) arasında nasıl görüldüğünü ve anlaşıldığını anlamak isterler (Elmusharaf 2016: 13). Bu araştırmada, İngiltere'de ana dili olarak Türkçenin eğitimini genel hatlarıyla tanımlamak, var olan sorunları belgelemek ve bunların çözümüne dair öneriler geliştirmek amaçlandığından veriler, bu işi gerçekleştiren öğretmenlerden toplanmıştır. Daha çok veriye ulaşmak ve gerçekçi yorumlarda bulunabilmek için öğretmenler arasında en üst düzeyde çeşitliliğin sağlandığı bir örnekleme başvurulmuştur. Bunun için odak grup görüşmesi, İngiltere'de uzun süredir çalışmakta olan, farklı ortamlarda öğretmenlik deneyimine sahip kişilerin olduğu çalışma grubuyla gerçekleştirilmiştir.

Odak grup görüşmesi, daha önce Londra Eğitim Müşavirliğinden alınan izine uygun olarak İngiltere'de Türkçe ve Türk Kültürü öğretmeni olarak görev yapan; araştırmaya katılmaya gönüllü, ses ve görüntü kaydı alınmasına izin vermiş olan, daha önce İngiltere'deki tüm Türkçe ve Türk Kültürü dersi eğitim ortamlarını deneyimlemiş beşi kadın ve beşi erkek olmak üzere toplam on öğretmen ile gerçekleştirilmiştir. Bu öğretmenlerin branş dağııımı şöyledir:

\begin{tabular}{lc} 
Branş & Öğretmen Sayısı \\
\hline Türkçe Öğretmeni & 2 \\
İngilizce Öğretmeni & 2 \\
Sınıf Öğretmeni & 2 \\
Din Kültürü ve Ahlak Bilgisi Öğretmeni & 2 \\
Sosyal Bilgiler Öğretmeni & 1 \\
Matematik Öğretmeni & 1 \\
Toplam & 10 \\
\hline
\end{tabular}

Grubun liderliğini Doç. Dr. Sami Baskın, raportörlüğünü de Dr. Mehmet Toyran yapmıştır.

\section{Veri Toplama Araçları}

Veriler yarı yapılandırılmış sorular vasıtasıyla elde edilmiştir. Bu sorular hazırlanırken Türkçe eğitimi alanında akademik çalışmaları olan, daha önce en az 2 sene yurt dışında Türkçe ve Türk Kültürü dersine girmiş 3 akademisyenin bilgisine danışılmıştır. Özellikle eğitim ortamları konusunda onların deneyimleri soruların hazırlanmasında yönlendirici olmuştur. Ayrıca çalışma, odak grup görüşmesi biçiminde gerçekleştiğinden soruların detaylandırılması aşamasında gruptakiler birbirine sorular sorması da bir fırsat olarak görülmüştür. Bu durum, grup etkileşimi ele alınan fenomenin daha ayrıntılı olarak ele alınmasına imkân sağlamıştır. 
1. Eğitim yapılan ortamlar ve bunların eğitim-öğretime etkisi (sınıflar, tahta, projeksiyon vb.) ile ilgili sorular:

- Eğitim yapılan ortamları tanıtabilir misiniz? Bu ortamların yaptığınız işe etkisi nedir? (Okulların mesafesi, sınıflar, destek materyaller, fotokopi, tahta, projeksiyon vb.)

- Eğitim yapılan ortamlardaki paydaşların (okul yönetimleri, diğer öğretmenler vb.) eğitimöğretime etkileri hakkında ne düşünüyorsunuz?

2. Türkçe ve Türk kültürü ders kitapları ve materyal kullanımı ile ilgili sorular:

- 2019-2020 yılında dağıtılan Türkçe ve Türk Kültürü ders kitaplarının yeterli ve seviyelere uygun olduğunu düşünüyor musunuz?

- Ders kitabı haricinde ne tür materyaller kullanıyorsunuz?

3. Öğrencilerin Türkçe dersine karşı tutumlarıyla ilgili sorunlar:

- Öğrencilerin Türkçe dersine dair genel tutumları nasıl?

- Sınıftaki öğrenciler arası seviye farkları oluyor mu? Varsa buna nasıl tedbirler alıyorsunuz? faaliyetleri)

- Öğrencilerin gelişim süreçlerini nasıl değerlendiriyorsunuz? (Ölçme ve değerlendirme

- Sınıftaki öğrenciler arasında seviye farkları var mıdır? Varsa buna nasıl tedbirler alıyorsunuz? faaliyetleri)

- Öğrencilerin gelişim süreçlerini nasıl değerlendiriyorsunuz? (Ölçme ve değerlendirme

4. Öğretmenlerin Türkçe ve Türk Kültürü dersine etkilerine dair sorular

- Farkıı branşların Türkçe ve Türk kültürü dersi vermelerinin yarattığı sorunlar var mı?

- Öğretmenler arası iş birliği hakkında ne düşünüyorsunuz? Beklenen ve istenen düzeyde mi?

5. Velilerin Türkçe ve Türk Kültürü dersine yaklaşımlarına dair sorular

- Veliler Türkçe ve Türk Kültürü derslerine yeterince ilgi gösteriyor mu?

- Veliler Türkçe ve Türk Kültürü öğretmenlerine yardımcı oluyor mu?

\section{İşlem / Verilerin Toplanması}

Bu çalışmadaki veriler, İngiltere'nin Londra, Hull, Bristol, Swindon, Northampton şehirlerinde görev yapan 10 öğretmenle 02 Mart 2021 tarihinde gerçekleştirilen odak grup görüşmesi ile toplanmıştır. Odak grup görüşmesi salgın koşulları ve öğretmenlerin farklı şehirlerde yaşıyor olmasından dolayı çevrimiçi ortamda (Zoom Video Communications) gerçekleşmiştir. Bu program hem ses hem de görüntü kaydı almaya imkân tanımıştır. Odak grup görüşmesi iki oturum halinde (her oturum ortalama 2 saat) gerçekleşmiştir.

Bireylerin düşüncelerini serbestçe söyleyebildiği bir ortamda yürütülen bir tartışma olarak tanımlanan odak grup görüşmesi, katılımcıların görüşlerinin ve bakış açılarının betimlenmesine olanak sağlamaktadır (Çokluk, Yılmaz ve Oğuz, 2011). Odak grup görüşmesi ile grupların psikolojik ve sosyokültürel özellikleri ya da yaptıkları uygulamalar hakkında bilgi almak, davranışlarının arkasında yatan nedenleri ve ortak algılamaları öğrenmek amaçlanır (Şahsuvaroğlu ve Ekşi, 2008).

\section{Verilerin Analizi}

Odak grup görüşmesine katılan kişilerin açık kimliği yerine her birine sırasıyla Ö1 (Öğretmen 1), Ö2 (Öğretmen 2) gibi kodlar verilmiştir. Metinler de Ö1'in metni, Ö2'nin metni şeklinde yazıldı. N ise var olan görüşe katılan kişi sayısını ifade etmektedir. (N7) ifadesi, "Bu düşünceyi görüşmeye katılan 7 öğretmen dile getirmiştir." anlamındadır.

Öğretmenlerin görüşleri ses ve görüntü kaydı ile toplanmıştır. Bu kayıtların yazılı dokümanları hazırlanmış ve metin analizleri yapılmıştır. Tespit edilen durumlar önce bir cümle ile ifade edilmiş, sonra bu yargının ortaya çıkmasına neden olan öğretmen görüşlerinden örnekler verilmiştir. Bunu bir örnek ile şöyle göstermek mümkündür:

- Cami dernek okulları birer ibadethane olarak inşa edilmiştir, eğitim öğretime uygun yerler değildir (N7). 
Örnekler:

Cami dernekleri ibadethane olarak inşa edilmiştir ve eğitimin doğasına göre düzenlenmemiştir (Ö1, Ö2, Ö5, Ö7, Ö9).

Cami okulları dini eğitim, Kur'an eğitimine dayalı bir düzene sahiptir (Ö2, Ö4, Ö6).

Bahçe veya çocukların hareket edebilecekleri bir alanları bulunmamaktadır (Ö1, Ö2, Ö5, Ö8, Ö10).

N7, bu görüşe katılan öğretmen sayısını; Ö1, Ö2 gibi adlandırmalar ise cevapların sahibi olan öğretmenleri göstermektedir.

\section{Geçerlik ve Güvenirlik}

Yarı yapılandırılmış sorular hazırlandığında daha önce en az iki sene yurt dışında çalışmış, Türkçe eğitimi alanında 1'i Prof. Dr. ve 2'si Doç. Dr. unvanına sahip uzmanlara danışımıştır. Onların yönlendirmeleri ile sorular hazırlanmıştır. Hazırlanan bu sorular, araştırmacılardan biri olan Mehmet Toyran'ın gözetiminde 3 kişiye yüz yüze ortamda Londra'da uygulanmıştır. Buradan alınan dönütlerle sorular tekrar gözden geçirilmiş, sonra uzmanlarla yine görüşülmüş ve soruların son biçimleri verilerek odak gruba uygulanmıştır. Odak grup görüşmesi kayıtları her iki araştırmacı tarafından ayrı ayrı analiz edilmiş ve bu analizler birbiriyle karşılaştırılmıştır. Böylece araştırmacılardan doğacak hatalar en aza indirilmiştir. Araştırma ile elde edilen sonuçlar daha önceki çalışmada elde edilen bulgularla, alan yazındaki diğer çalışmalarla ve başta T.C. Londra Eğitim Müşavirliği olmak üzere çeşitli kurumların yayımladığı raporlardaki bilgilerle karşılaştırıımıştır.

\section{Araştırma ve Yayın Etiği}

Bu çalışmada "Yükseköğretim Kurumları Bilimsel Araştırma ve Yayın Etiği Yönergesi" kapsamında uyulması belirtilen tüm kurallara uyulmuştur. Yönergenin ikinci bölümü olan "Bilimsel Araştırma ve Yayın Etiğine Aykırı Eylemler" başlığı altında belirtilen eylemlerden hiçbiri gerçekleştirilmemiştir.

Bu araştırma için hem T.C. Londra Eğitim Müşavirliğinden izin hem de Tokat Gaziosmanpaşa Üniversitesi Sosyal ve Beşerî Bilimler Araştırmaları Etik Kurulu'ndan rapor alınmıştır.

\section{Araștırma İzni}

Kurul adı= T.C. Londra Eğitim Müşavirliği

Karar tarihi $=01.01 .2021$

Belge sayı numarası $=134$

\section{Etik Kurul İzni}

Kurul adı= Tokat Gaziosmanpaşa Üniversitesi, Sosyal ve Beşeri Bilimler Araştırmaları Etik

Kurulu

Karar tarihi $=12.02 .2021$

Belge sayı numarası $=12166$

\section{Bulgular}

Bu araştırmanın bulguları temelde İngiltere'de görev yapan 10 Türkçe ve Türk Kültürü Dersi öğretmenine dayanmaktadır. Ancak bu öğretmenlerle yapılan odak grup görüşmesinden elde edilen bulguların anlamlandırılabilmesi ve gerçekliklerinin daha iyi anlaşılabilmesi için söz konusu bulgular sınıflandırılarak bölümlere ayrılmıştır. Her bölüm de üç aşamada düzenlenmiştir. Birinci aşamada literatürde var olan bilgilerden yararlanılarak bölüme dair betimlemeler yapılmıştır. İkinci aşamada öğretmenlerden elde edilen bulgulara yer verilmiştir. Üçüncü aşamada ise konu bütünlüğünün sağlanabilmesi adına elde edilen bulgular özetlenmiştir.

\section{Eğitim yapılan ortamlar ve bunların eğitim-öğretime etkisi (sınıflar, tahta, projeksiyon vb.)}

Londra Eğitim Müşavirliğinden alınan verilere göre İngiltere genelinde Türkiye'den gelenlerin kurduğu Türk dernek okulları (28), Kıbrıslı Türk dernek okulları (7), Cami derneği okulları (14) ve İngiliz 
okullarında (45) toplam 94 okulda Türkçe ve Türk Kültürü öğretimi yapılmaktadır. Kuruluş açısından bir farklıığı bulunmayan bu kurumların içerik ve işlevleri birbirinden farklı olabilmektedir. Kâr amacı gütmeyen bu kurumların bir kısmı ibadethanelerin faaliyetini genişletmek maksadıyla kurulmuş cami dernekleridir. Bir kısmı ise Kıbrıs'tan ve Türkiye'den göçmüş Türklerin çocuklarına Türkçeyi öğretmek amacıyla kurdukları, daha çok etüt mahiyetinde faaliyet gösteren derneklerdir.

Dernek okullarının 35 tanesi Londra'da, 14 tanesi de Londra dışındadır. Dernek okullarında 2020 Aralık ayı itibarıyla toplam 1497 Türk öğrenci Türkçe ve Türk Kültürü dersini almaktadır. Bu dersler haftada 2 ile 4 saat arasında değişmektedir. Bu derslerin saatine okullar karar vermektedir. İngiltere'de Türkçe ve Türk Kültürü derslerinin yapıldığı klasik anlamda okul olarak adlandırılabilecek müstakil bir bina bulunmamaktadır. Cami derneği okullarında, dersler cami içerisinde veya ayrılmış küçük bir odada yapılmaktadır. İçerisinde derslikler bulunan camiler olsa da (Aziziye Cami Okulu, Hull Türk Diyanet Cami Okulu vb.) bunların sayısı fazla değildir. Cami derneği biçiminde olmayan dernek okullarında Türkçe ve Türk Kültürü dersi, genellikle İngiliz okullarında ya da belediyeden kiralanmış dersliklerde yürütülmektedir.

Londra Eğitim Müşavirliğinden alınan verilere göre İngiltere genelinde 45 İngiliz okulunda 1044 öğrenci Türkçe ve Türk Kültürü dersi görmektedir. Türkçe eğitimi Primary ve Secondary olarak adlandırılan okullarda sosyal kulüp (after school club) dersleri şeklinde yapılmaktadır. Secondary okullarındaki Türkçe ve Türk Kültürü dersleri genellikle lise bitirme sınavları olarak adlandırılabilecek GCSE Turkish (General Certificate of Secondary) ile üniversiteye giriş sınavları olan A Level Turkish (Advanced Level) esas alınarak sınıf ortamlarında yapılmaktadır. Primary okullarında sınav hazırlığı söz konusu değildir.

Türkçe ve Türk Kültürü dersinin yapıldığı ortamlar ve bunların eğitim-öğretime etkisi ile ilgili öğretmen görüşleri şu şekildedir:

- Cami dernek okulları birer ibadethane olarak inşa edilmiştir, eğitim öğretime uygun yerler değildir (N7).

Örnekler:

Cami dernekleri ibadethane olarak inşa edilmiştir ve eğitimin doğasına göre düzenlenmemiştir (Ö1, Ö2, Ö5, Ö7, Ö9).

Cami okulları dini eğitim, Kur'an eğitimine dayalı bir düzene sahiptir (Ö2, Ö4, Ö6). Ö10).

Bahçe veya çocukların hareket edebilecekleri bir alanları bulunmamaktadır (Ö1, Ö2, Ö5, Ö8,

- Cami dernek okullarında bir sınıf düzeni ve ortamı yoktur (N3).

Örnekler:

Insanlar sınıfın içinden geçerek veya sınıftakileri gözetleyerek ibadet alanına geçmektedir, bu da öğrencilerin dikkatini dağıtıyor (Ö1, Ö7, Ö9).

- Cami dernek okullarında eğitim alanları oldukça dardır (N6).

Örnekler:

Eğitim verilen alan çok dar, sınıflar ancak beşer altışar olabilmektedir (Ö1, Ö5, Ö7, Ö9).

Caminin ortasında perde çekilmiş bir yanda kızlar bir yanda erkekler ders görüyor. Sesler birbirine karışıyor. Gruplar birbirlerini uyarabiliyor (Ö7). Ö10).

Koridorda ders yapıyorum, cami okulunda, fiziksel imkânsızlıklar çok fazla (Ö1, Ö2, Ö5, Ö7, Ö9,

- Bazı Cami dernek okulları dersler için özel alanlara sahiptir (N2).

Örnekler:

Yeni açılan cami okulumuzda fiziki ortam açısından normal bir okulda bulabileceğiniz her türlü imkânı bulabilirsiniz (Ö4, Ö8).

Geçen yıl açılan ve benim gittiğim cami okulunda derslikler ve bütün imkânlar var (Ö4, Ö8).

- İngiliz okulları ya da belediyenin hizmet binalarını kiralayan Türk dernek okullarında eğitim ortamı nispeten daha iyidir (N6).

Örnekler:

İngiliz okullarını kiralayan Türk Dernek okulları bir eğitim öğretim ortamı, sınıf ortamı olduğu için daha verimli geçebiliyor dersler (Ö1, Ö4, Ö7, Ö9). 
Londra dışında bir halk eğitim merkezinde Türkçe dersleri veriyorum. Orada eğitim ortamı çok olumlu (Ö6).

Türkçe dersinin öneminin farkındaysa okul, size bütün olanakları açıyor (Ö3, Ö5, Ö10).

- Türk dernek okullarında, ders araç-gereçleri konusunda bazen sıkıntılar yaşanabilmektedir (N4).

\section{Örnekler:}

Kendimize ait pano oluşturamıyor, öğrencilerin yaptığı etkinlikleri herhangi bir yerde kalıcı olarak sergileyemiyoruz. Sınıflarda projeksiyon yok, sınıf mevcutları çok az olduğu için yani laptopla ya da hoparlörle dinleme etkinlikleri yapabiliyoruz (Ö3).

İngiliz okullarından sınıf kiralayan derneklerin eğitim sürecinde de sıkıntılar mevcuttur. Okulun fotokopi sorunu var. Projektörü kullanmanıza izin vermiyorlar, akıllı tahtalar şifreli, kullanamıyorsun. Dört saat dersim var ve bu 4 saat elimdeki tek şey tahta, kâğıt ve kalem (Ö5, Ö9).

Dernek okullarında ders materyalleri konusunda sıkıntılar yaşanıyor (Ö1, Ö5, Ö7, Ö10).

İngiliz okullarında çok renkli, cafcaflı, şatafatlı malzemeler kullanıyorlar. Siz onlara kötü bir fotokopi götürdüğünüzde sizin bir kıymetiniz olmuyor (Ö5).

- Okul yönetiminin ders ortamının eğitime uygun hâle getirilmesinde etkisi çok fazladır (N3).

Örnekler:

Gittiğim okulda okul yönetimi o kadar çok ilgiliydiler ki öğrenciler için stickerlar, hediyeler, öğrencilerinin kullanacakları küçük tahtalar, renkli parlak parlak kalemler, oyuncaklar alıyorlardı (Ö9).

- İngiliz okullarında ders saatlerinden sonra yapılan kulüp etkinliği biçimindeki Türkçe dersleri sınıf ortamlarının sunduğu bütün imkânlarla yapılabilmektedir (N7).

Örnekler:

İngiliz okullarında bütün imkânlar oluyor (Ö1, Ö2, Ö4, Ö5, Ö7, Ö9, Ö10).

İngiliz okulundaki okulun yönetimi çok büyük bir motivasyon kaynağı (Ö6).

-Türkçe GCSE ve Türkçe A level sınav hazırlığı yapan okullar, Türkçe derslerine daha fazla önem vermektedir (N4).

Örnekler:

Sınavlar okulların genel puanlarına etki ettiği için Türkçe dersi için bütün imkânları sağlıyorlar (Ö3, Ö5, Ö8).

Bazı okullar dil okulu gibi davranıyorlar ve başarılarının da reklamını yapabiliyorlar. Bu yüzden sınav hazırlığı onlar için çok önemli (Ö10).

İngiltere'de Türkçe ve Türk kültürü dersleri cami okullarında, İngiliz okullarında veya kültür merkezlerinde yapılmaktadır. Cami okullarındaki ders ortamları eğitim için inşa edilmemiş olduğundan Türkçe eğitimi bu ortamlarda çok verimli olmamaktadır. Sınıf ortamlarına, destek materyallerine sahip cami dernek okullarının sayısı oldukça azdır. Akşamları ya da hafta sonları İngiliz okullarından ya da belediyelerin hizmet binalarından derslikler kiralayarak eğitim-öğretim yapan Türk dernek okullarında eğitim ortamları okulun sunduğu imkânlar nispetince gerçekleşmektedir. Kiralanan bazı okullar akıllı tahta, projeksiyon gibi materyalleri kullandıırken çoğunluğu buna izin vermemektedir. Türk dernek okullarındaki yöneticiler ders ortamlarının niteliğini önemli ölçüde etkilemektedir. Bazı okul yöneticileri eğitim için gerekli olan destek materyallerini temin etme konusunda daha duyarlıyken bazı yöneticiler fotokopi, tahta kalemi gibi temel materyalleri bile temin etmemektedir. İngiliz okullarında ders sonrası (after school club) yapılan Türkçe derslerinde eğitim ortamlarının kullanımı okul yönetimlerinin yaklaşımlarına göre değişmekle beraber bu ortamlar dernek okullarından daha elverişli öğrenme ortamları sunmaktadır. Özellikle GCSE ve A Level Turkish sınavına öğrenci hazırlayan okullarda Türkçe ve Türk Kültürü öğretmenleri eğitim ortamlarının bütün imkânlarını kullanabilmektedir. Bu da İngiltere'de Türkçe ve Türk Kültürü dersinin yapıldığı yerlerin bir standardının olmadığını açıkça göstermektedir.

\section{Türkçe ve Türk Kültürü ders kitaplarının kullanımı}

Yurt dışındaki Türkçe ve Türk Kültürü dersleri MEB tarafından 2018 yılında güncellenen Türkçe ve Türk Kültürü Dersi Öğretim Programı'na göre yapılmaktadır. Programın hedefi şu cümlelerle ifade edilmiştir: "Türkçe ve Türk Kültürü dersinde öğrencilerin kendi kültürlerini öğrenmeleri, içinde 
yaşadıkları toplumun kültürü ve farklı milletlerden arkadaşlarının kültürleriyle kendi kültürlerini karşılaştırmaları, benzerlik ve farklılıkları tanıyıp anlamlandırmaları hedeflenmektedir". Programda Türkçe ve Türk Kültürü öğretiminin sekiz seviye hâlinde verilmesi öngörülmüştür. MEB tarafından bu seviyelere uygun hazırlanan ders kitapları 2019-2020 yılında öğrencilere dağıtılmıştır. 2020-2021 eğitim-öğretim yılında ise salgın sebebiyle çevrim içi eğitime geçildiğinden öğrencilere matbu kitaplar dağıtılmamıştır. Türkçe ve Türk Kültürü ders kitapları 1.Ben ve Ailem, 2.Çevre, Farklılıklar ve Birlikte Yaşama, 3. Oyun ve Eğlence, 4. Bayramlar ve Kutlamalar, 5. Gezelim Görelim, 6.Geçmişe Açılan Kapı, 7. Sanat ve Edebiyat, 8. İnsan ve Doğa temalarına göre yapılandırılmıştır. T.C. Londra Eğitim Müşavirliğine bağıı olarak çalışan öğretmenler, MEB kitaplarının yanı sıra Doç. Dr. Nihal Çalışkan ve Dr. Mehmet Toyran editörlüğünde hazırlanan Türkçe ve Türk Kültürü Ders Materyalleri kitabını, kendi hazırladıkları materyalleri ve eğitim içeriği barındıran sitelerden aldıkları materyalleri kullanmaktadır.

Derslerde materyal kullanımına dair öğretmen görüşleri şu şekildedir:

- Ders kitapları sistematik bir eğitim sunduğu için çok faydalıdır (N6).

Örnekler:

6 yaşından 16 yaşına kadar çocuklar var sınıfta ve bunların hepsine ayrı ayrı materyal hazırlıyordum. Kitaplar gelince bu kadar yorulmadım, rahatlattı beni (Ö3, Ö5, Ö7, Ö10).

Kitaplardaki kaligrafi, renklendirme, kalın puntolar, ilgi çekicilik düşünüldüğünde kitaplar çok olumlu, özellikle kare kod uygulaması çok pratik (Ö1, Ö2).

Tematik yaklaşım bir konuda derinleşmek açısından çok faydalı. Kitaplar da bu imkânları sunuyor (Ö4).

Olumlu ve olumsuz tarafları da var kitapların ama genel anlamda iyi $(0 ̈ 5,0 ̈ 9)$.

- Ders kitapları içerik açısından İngiltere için yeterli değildir (N3).

Örnekler:

Kitapların içerikleri kazanımlarla örtüşmüyor. İçerikte tanımlanan kelimelerin bir sözlükle desteklenmesi gerektiğini düşünüyorum (Ö1, Ö6, Ö7).

Ben bu sene hiç kitap kullanmıyorum. Çünkü hiç seviyesine uygun olduğunu düşünmüyorum.

2. seviye kitabıyla 3. seviye kitabı arasında büyük bir uçurum var. 2. seviye kitabında bir alfabe çalışmaları var, hece çalışmaları var çok küçük metinlerle sonlandırıyor (Ö7).

Bu kitaplar aslında İngiltere için değil tüm yurt dışında, Avrupa'da öğretilmek üzere hazırlanmış kitaplar. Sıkıntılar buradan kaynaklanıyor (Ö2, Ö6).

- Kitaplar görsel olarak güzel hazırlanmış ama teknik bazı sorunlar içermektedir (N3).

Örnekler:

Ö10).

Karekodlar var ama kare kodların hepsi çalışmıyor veya çok uzun dinleme metinleri var (Ö3,

Dinlemeler çok uzun, daha kısa olabilir ve daha güzel dinleme etkinlikleri yapılabilir (Ö9).

Karekodları da faydalı buluyorum birkaç tane Kültür Bakanlığına ait müzeleri gezme çalışmasa da (Ö10).

- Türkçe ve Türk Kültürü dersleri sadece kitaplardan işlenmemeli, kaynaklar çeşitlendirilmelidir (N9).

\section{Örnekler:}

İnternetten "Serhat Hoca, ilkokul 1" gibi sitelerden yararlanıyorum. İngiliz sitelerinden twinkle gibi sitelere bakıp o seviyedeki çocukların alışkın olduğu şeyleri bulmaya çalışıyorum (Ö7).

Kendim materyal hazırlıyorum çocuklara. Türkiye'den getirdiğim kitapları kullanıyorum (Ö1, Ö3, Ö5, Ö7, Ö9).

Online kaynak sınırsız, çok güzel kaynaklar bulunabiliyor internetten, biz de hazırlıyoruz (Ö4, Ö6).

Kahoot ve Wordwall'ı kullanıyorum, zaman zaman Eğitimhane'den de faydalanıyorum (Ö8).

Dijital platformlar da kullanıyorum ben Liveworksheets kullanıyorum, Google Classroom kullanıyorum onlardan da memnunum (Ö5).

Türkçe, Türk kültürü eğitimi yapıyorsanız mutlaka materyal hazırlamak, kendi içeriğinizi oluşturmak durumundasınız yoksa gerçekten sınıftan görmek istediğiniz verimi alamazsınız (Ö1, Ö2, 0̈3, 0̈4, Ö5, 0̈6, Ö7, Ö10). 
Illk geldiğimde kendi materyallerimi hazırlıyordum. Okulistik, Morpa ve Testmoz da kullanıyorum (Ö10).

Millî Eğitim Bakanlığı 2019-2020 eğitim-öğretim yılında İngiltere'deki Türkçe ve Türk Kültürü dersleri için Hazırlık 1-2 ders kitaplarının yanı sıra 8 seviyede 3114 kitap göndermiştir. 2020-2021 eğitim-öğretim yılında kitapların güncellenmesi, salgın koşulları vb. sebepler yüzünden İngiltere'ye basılı kitaplar gönderilmemiştir. Öğretmenler mevcut kitapların dijital hâllerini çevrim içi derslerde kullanmaktadır. Türkçe ve Türk Kültürü ders kitaplarının kullanımı ile ilgili bir zorunluluk yoktur. Bu nedenle öğretmenlerin ders kitaplarına yaklaşımları farklıık göstermektedir. Öğretmenler Türkçe ve Türk Kültürü dersinin sadece kitaplardan işlenmemesi, kaynakların çeşitlendirilmesi konusunda hemfikirdirler. Öğretmenler; sistematik ve tematik ilerleme imkânı sunması, birleştirilmiş sınıflardaki öğrencilere hitap edebilmesi, görsellik açısından doyurucu olması gibi sebeplerden ders kitaplarını tercih etmektedir. Bunun yanı sıra bazı öğretmenler ders kitaplarının seviyelere uygun olmadığını düşünerek bu kaynakları kullanmamaktadır. MEB tarafından gönderilen kitapların yanı sıra öğretmenler derslerde hem kendi hazırladıkları hem de eğitim içerikli sitelerden aldıkları materyalleri kullanmaktadır. Onlar; Serhat Hoca, ilkokul 1, kahoot, wordwall, eğitimhane, liveworksheet, Google classroom, okulistik, morpa, testmoz gibi siteleri tercih etmektedir. Öğretmenler, Türkçe ve Türk Kültürü ders kitaplarının ülkelerin genel yapılarına uygun olarak güncellenmesi, özellikle dinleme metinlerinin uzunluklarına dikkat edilmesi, öğrenci seviyelerine uygunluk açısından da yeniden gözden geçirilmesi gerektiğini düşünmektedir.

\section{Öğrencilerin Türkçe Dersine Karşı Ilgisi}

T.C. Londra Eğitim Müşavirliğinin Aralık 2020 tarihli verilerine göre İngiliz okullarında ders sonrası 1044, Türk dernek okullarında 690, cami dernek okullarında da 807 öğrenci olmak üzere toplam 2541 kişi Türkçe ve Türk Kültürü dersi almaktadır. Bu öğrenciler 5-18 yaş aralığındadır. Yılsonunda öğrencilere ders öğretmenleri tarafından hazırlanan ve dört temel dil becerisiyle ilgili görüşlerin yazıldığı gelişim raporları verilmektedir. Sınıflarda öğrenci sayıları 3 ile 20 arasında değişebilmektedir. Öğrencilerin seviyelerini belirlemek için dönem başında ders öğretmenleri seviye tespit sınavı yapmaktadır. 2020 Kasım ayında www.testmoz.com üzerinden 509 öğrenciye "Kazanım Değerlendirme Sınavı" (KDS) uygulanmıştır. Çevrim içi gerçekleşen bu sınavın ikincisi Haziran 2021'de yapılacaktır. Öğretmenlerin; öğrencilerin seviyeleri, hazırbulunuşluk düzeyleri, ölçme ve değerlendirme süreçleri ile ilgili görüşleri şu şekildedir:

- Öğrencilerin Türkçe dersine dair tutumları değişkenlik göstermektedir (N10).

\section{Örnekler:}

GCSE ve A Level öğrencileri sınava yönelik çalıştıkları için daha istekli oluyorlar. Ama çok uluslu evliliklerde anne Türk ya da baba Türk olunca biraz annenin babanın zoruyla geliyor çocuklar (Ö2, Ö5).

Cami okuluna giden ve Türkçe konuşup anlayabilen öğrenciler Türkçe bildiklerini düşündükleri için derslere gereken özeni göstermiyorlar (Ö8).

Aileye göre, çocuğa göre bazen istekli bazen isteksiz olabiliyorlar (Ö6, Ö9).

- Öğrencilerin derse karşı ilgilerinde velilerin tutumu belirleyicidir (N3).

Örnekler:

Türkçe derslerinin önemli olduğunun farkına varan veliler, öğrencilerle karşılaşabiliyoruz, bunlar da motivasyonumuzu devam ettiriyor (Ö8, Ö10).

Veli ev içerisinde Türkçe okuryazarsa çocuğun da o hassasiyette oluyor (Ö4).

- Öğrencilerin derse karşı ilgilerinde öğretmenlerin çabası belirleyicidir (N6).

Örnekler:

Öğrencilerimizin çoğu ailelerin baskısıyla geliyor. Çocuklar çok istekli gelmedikleri için yük öğretmenlere düşüyor. Güzel etkinlikler yaparsak çocuklar çok seviyor öbür hafta dört gözle geliyor (Ö3, Ö4, Ö6, Ö7).

Öğrencilerimizin genel olarak hazır bulunuşluk düzeyi memnun edici değil. Sürekli performansınızı yukarıda tutmanız gerekiyor (Ö1, Ö6). 
Ailenin tutumu, öğretmenin iletişimi ve yaptığı etkinlikler önemli. Bazen stickerlar, hediyeler veriyoruz çocuklara. İngiliz okullarında uygulanan teknikleri biz de kendi derslerimiz uygularsak zaten alışık oldukları şeyler olduğu için hoşlarına gidiyor (Ö9).

-Öğrenci seviyeleri arasındaki farklar eğitim öğretimi etkileyebiliyor (N5).

Örnekler:

Sene başında öğrencilere uyguladığım birtakım seviye belirleme testleri var. Ama seviyelere göre okul içinde başka sınıflar oluşturma imkânı olmuyor, bu sebeple sınıf içindeki farklı seviyelere göre ders hazırıklarını yapıyoruz (Ö9).

Sınıf içindeki farklı seviyelerdeki öğrencilere farklı etkinlikler hazırlamak kimi zaman zor oluyor bizim için (Ö1, Ö3, Ö4, Ö7, Ö9).

- Sınıftaki öğrencilerin seviyesine öğretmenler karar veriyor (N3).

Örnekler:

2 haftalık deneme süresinden sonra sınıf seviyelerine dair karar veriyorum (Ö10).

Sene başında ilk 2-3 haftayı çocukları tanımak için, yaşına göre, dil seviyesine göre gruplandırmak için harcıyorum. Tabi 5 farklı grupla çalıştığınız için bu çok sürdürülebilir olmuyor ama biraz daha süreç odaklı (Ö4).

Ben 3 yıldır aynı bölgede görev yapıyorum. Aynı bölgede görev yaptığım için öğrencilerimi 1. sınıftan alıp 3. sınıfa geçirmiş gibi, artık öğrencimizi tanıyoruz, o yüzden sınıfları belirlemede kendi değerlendirmemi yapıyorum (Ö8).

Online eğitim sürecinde yaklaşık 96 öğrencim oldu. Sınıfları ayırırken daha güzel ayarlayabildik ama burada kesinlikle homojen bir sınıf oluşturmanız mümkün değil (Ö5, Ö10).

-Öğrencilerin gelişim süreçlerini mutlaka ölçmek gerekiyor (N6).

Örnekler:

Karne var yılsonunda; okuma becerisi, dinleme becerisi, konuşma becerisi ile ilgili paragraflar şeklinde yazıyoruz (Ö2, Ö6, Ö9).

Online ortamda okuma ve dinleme becerilerini ölçen KDS bu yıl için çok güzel bir sınavdı, devam etmesi gerekiyor (Ö1, Ö2, Ö4, Ö7, Ö9, Ö10).

KDS öğrencinin eksiğini göstermesi açısından güzel oldu. Online olarak sınıfa 8-10 kişinin katııırdı, sınavın yapıldığı gün bu sayı 14-15'i buldu. Bu durum çocukları çok güdüledi, çok rekabet ortamı yarattı (Ö7).

Öğrencilere mutlaka geribildirimlerde bulunulması gerekir. İnsanlığın doğası gereği kendinin ne yaptığını bilmesini ister çocuklar merak ediyorlar. Sınav yaptığım dönemde de çok soruyorlardı sonuçları (Ö2, Ö8).

Kazanım değerlendirme sınavlarında ve diğer ölçme ve değerlendirme araçlarında dört temel dil becerisinin de ayrı ayrı ölçülmesi gerekmektedir (Ö4).

-Öğretmenlerin, özellikle Londra'daki okullarda, her yıl farklı okullarda görevlendirilmesi genel tutumlarını olumsuz etkiliyor (N3).

Örnekler:

Öğrenci gelecek yıl ona Türkçe öğretmeyeceğimizi biliyor bu yüzden yaptığımız işte bir devamlılık olmuyor (Ö7, Ö10).

Ben üç yıldır Hull şehrinde görev yaptığım için hem öğrencilerin seviyelerini hem de genel durumlarını çok iyi biliyorum, Londra'da görevlendirmeler her yıl değişiyor (Ö8).

- Ulusal sınavlara hazırlık süreçleri öğrencilerin Türkçe ve Türk Kültürü dersine ilgilerini etkiliyor (N5).

Örnekler:

GCSE ve Level Türkçe sınavlarına hazırlanan öğrencilerin daha çok çalışması gerekiyor, öğrenciler de bu sınavların öneminin farkında oldukları için Türkçe ve Türk Kültürü dersine daha çok çalışıyorlar (Ö5, Ö7, Ö9, Ö10).

Türkçe GCSE ve A level sınavları öğrencilerin iyi bir üniversiteye gitmelerine katkı sunuyor (Ö3).

GCSE ve A Level Türkçe sınavında öğrencinin dört temel dil becerisini de geliştirmesi gerekmektedir (Ö5). 
Ingiltere'de Türkçe ve Türk Kültürü derslerine devam etmek genellikle aile isteği, hatta çoğu zaman zorlamasıyla gerçekleşmektedir. Bu başta olumsuz bir durum olsa da öğretmenlerin çabası bunun aşılmasına vesile olmaktadır. Öğrenciler iyi vakit geçirdikleri Türkçe ve Türk Kültürü derslerini dört gözle beklemeye başlamaktadır. Aksi bir durum öğrencilerin kaybedilmesine neden olmaktadır.

Özellikle cami okullarında eğitim gören çocuklar, "Zaten Türkçe biliyorum." düşüncesine sahip olduklarından derslere diğer öğrencilerden daha isteksizdirler. Farklı seviyelerdeki öğrencilerin aynı sınıflarda eğitim görmesi, eğitim-öğretimi olumsuz etkilemektedir. Bunun yanında öğrencilerin her yıl farklı bir öğretmenle ders yapacaklarını bilmeleri motivasyonlarını düşürmektedir. Londra'da görev yapan öğretmenler her yıl farklı okullara görevlendirilmektedir. Bu öğretmenler, sene başlarında 2-3 hafta öğrencilerin seviyelerini belirlemek için çabalamaktadır. Oysa Londra dışında Hull, Bristol, New Port, Luton gibi şehirlerde görev yapan öğretmenler uzun süre aynı şehirde çalıştıklarından öğrencileri tanımakta ve onların seviyelerine uygun derslere daha erken başlamaktadır.

Dört temel dil becerisini ölçen GCSE ve A Level Turkish sınavlarına hazırlananlar (16-18 yaş dilimindeki çocuklar) derslere daha ilgilidir. Türkçe ve Türk Kültürü Öğretim Programı́nda Türkçe ve Türk kültürü derslerinin akademik başarıya yönelik dersler olmadığı, kültürel faaliyetleri esas aldığı belirtilmiştir. Bu derslerde öğretmenler kendi amaçları doğrultusunda kontrol listesi, dereceli puanlama anahtarı, öz değerlendirme, akran değerlendirmesi, sınıf içerisinde hazırlanan gözlemler, formlar bunlarla öğrencilerin durumlarını kayıt altında tutmalıdır (Türkçe ve Türk Kültürü Öğretim Programı, 2018: 3). İngiltere'de Türkçe ve Türk Kültürü öğretimi alan öğrencilere yılsonunda dört temel dil becerilerine dair gelişim raporu verilmektedir. 2020 yılı Kasım ayında öğrencilerin dil becerilerini ölçmek için çevrim içi derslere katılan ve yaşları uygun olan 509 öğrenciye Kazanım Değerlendirme Sınavı (KDS) uygulanmıştır. Haziran ayında yapılacak olan ikinci sınavdan sonra öğrencilerin gelişim süreçleri verilere dayalı olarak değerlendirilebilecektir. Öğretmenlerin KDS sınavına yaklaşımları genellikle olumludur. Şimdilik okuma ve dinleme becerilerine yönelik bir sınav olan KDS'nin ilerleyen zamanlarda dört temel dil becerisinin de ölçülebileceği bir sınav haline gelmesi hedeflenmektedir.

\section{Öğretmenlerin Türkçe ve Türk Kültürü dersine etkileri}

Türkçe ve Türk Kültürü öğretmenleri 2003 yılında yürürlüğe giren Bakanlıklar Arası Ortak Kültür Komisyonu (BAOKK) kararıyla görevlendirilmektedir. Avrupa ülkelerinde görevlendirilen Türkçe ve Türk Kültürü öğretmenleri yabancı dil sınavı, ÖSYM tarafından yapılan yazılı sınav ve Millî Eğitim Bakanlığııın mülakat sınavında başarılı olmalıdır. Farklı branşlardan öğretmenler Türkçe ve Türk Kültürü öğretmeni olarak görevlendirildikleri için göreve başlamadan önce MEB tarafından uyum semineri organize edilmektedir. Görevlerine başlayan öğretmenler bakanlığın Türkçe ve Türk Kültürü Öğretim Programı (2018) doğrultusunda eğitim-öğretim faaliyetlerine devam etmektedirler. Türkçe ve Türk Kültürü öğretmenleri her sene yeniden güncellenmesi kaydıyla yurt dışında beş yıl görev yapabilmektedir. İngiltere'de 5'i Türkçe Eğitimi, 7'si Türk Dili ve Edebiyatı, 9'u Sınıf Öğretmenliği, 8'i İngilizce Eğitimi, 4'ü Din Kültürü ve Ahlak Bilgisi, 2'si Muhasebe, 1'i Sosyal Bilgiler Eğitimi, 1'i Matematik Eğitimi, 1'i de PDR alanından mezun toplam 38 öğretmen Türkçe ve Türk Kültürü dersini öğretmek üzere görev yapmaktadır. Bunun yanında KKTC tarafından görevlendirilmiş 11 öğretmen ve İngiltere'de bulunan gönüllü öğretmenler de Türkçe ve Türk Kültürü öğretimine katkıda bulunmaktadır.

- Farklı branşlardan öğretmenlerin Türkçe ve Türk Kültürü öğretmenliği yapmasının bazı dezavantajları vardır (N5).

Örnekler:

Ben ilk zamanlarda burası için sınıf öğretmenleri gelmeli diye düşünüyordum çünkü genel olarak öğrencilerin yaşları çok küçük (Ö3, Ö9).

Ben bir matematik öğretmeni olarak ilk başlarda çok zorlandım (Ö5).

Branşım din kültürü olduğu için iki kat daha fazla çalıştım (Ö7).

Herkesin ilk 5-6 ayı tamamen staj. Burada da bu işi belirleyen branştan ziyade gözlem yeteneği oluyor (Ö2).

-Uyum sürecinden sonra branşın bir önemi kalmıyor. Öğretmenlik yeteneği ile belirleyici oluyor (N5). 
Örnekler:

Ben ilk geldiğim zaman belirli branşların buraya gelmesi gerektiğini düşünüyordum ama şunu gördüm branştan ziyade bir insanın işine ne kadar kıymet verdiği, sorumluluk sahibi olduğu ve işini ne kadar severek yaptığının önemli olduğunu düşünüyorum (Ö1, Ö2, Ö9).

Zamanla fark ediyorsunuz ki gerçekten amaca, hedefe, etkinliklere hâkimseniz branşınız önemli değil Türkçeye hâkimseniz burada kolaylıkla yapabiliyorsunuz (Ö3, Ö8).

Ben Türkçe öğretmeniyim, ben de pek çok konuda, işte farklı yaş grubu ile çalışmak konusunda, ben de bir süre zorlandım ve yeni yöntemler geliştirmek zorunda kaldım (Ö4).

Ben İngilizce öğretmeni olmanın çok artısını gördüm (Ö6).

- Farklı bölge ve okullarda çalışmalarına rağmen öğretmenler arası iş birliği yapılmakta ve birbirlerine destek olunmaktadır (N6).

Örnekler:

Birbirimizle materyal paylaşıyoruz, deneyimlerimizi paylaşıyoruz, etkinliklerimizi paylaşıyoruz (0̈4, Ö9).

Online eğitim süreci ilişkileri etkilese de öğretmenler arası tecrübe aktarımı üst düzeyde (Ö1, Ö3, Ö6).

Farklı uzmanlık alanlarına sahip öğretmenler, İngiltere'de Türkçe ve Türk Kültürü öğretmeni olarak görevlendirilmiştir. İlk bakışta Türkçe Eğitimi, Türk Dili ve Edebiyatı, Sınıf Öğretmenliği, İngilizce Eğitimi gibi alanlardan mezun olanların daha avantajlı olduğu düşünülse de uyum sürecinden sonra, Türkçeye hâkim olan, iletişim becerileri gelişmiş öğretmenler ön plana çıkmaktadır. Ancak bu her zaman geçerli bir durum değildir. Öğretmenlerin İngiltere'deki ortama, dersin müfredatına uyum süreci bazen 6 ay, bazen de daha uzun bir süreyi gerektirmektedir. Türkçe ve Türk Kültürü dersleri için görevlendirilecek öğretmenlerin Türkçe, Türk Dili ve Edebiyatı, İngilizce gibi dil ağırıklı bir bölümden mezun olmaları bu uyum sürecini en aza indirecektir.

Yurt dışı öğretmenliği uyum semineri, genel olarak faydalı olsa da Türkçe ve Türk Kültürü dersinin nasıl öğretileceği konusunda özel bir hazırık imkânı sunmamaktadır. Bu seminerin ülkelerin faklı sosyo-ekonomik yapılarına göre düzenlenmesi ve öğretmenlerin gidecekleri yer ile ilgili bilgi edinmelerinin sağlanması görevlendirilenlerin işini kolaylaştıracaktır. İngiltere'de okullar arasındaki mesafe yüzünden bütün öğretmenlerin birbiriyle görüşmeleri mümkün değildir. Ancak teknolojinin imkânlarını kullanan öğretmenlerin birbirleriyle materyal ve tecrübe paylaşımı üst düzeydedir.

\section{Velilerin Türkçe ve Türk Kültürü Dersine Yaklaşımı}

Ingiltere'de, Türkiye'den ve Kuzey Kıbrıs Türk Cumhuriyetinden gelen veliler bulunmaktadır. Genel olarak ana dilleri Türkçe olsa da bazı çocukların velilerinin (anne ya da baba) yabancı uyruklu olması da oldukça yaygındır. Öğrenciler İngiliz okullarında eğitim aldıkları için bütün çocukların İngilizcelerinin çok iyi olduğu görülmektedir. Veliler, çocuklarının Türkçe ve Türk kültüründen kopmaması için onları hafta sonu Türk okullarına göndermektedir. İngiliz okullarında Türkçe sınıfı açtırmak isteyen veliler ise okul idarelerine dilekçe vererek bu isteklerini gerçekleştirebilmektedir. Açılan bu okullar, öğrencilere eğitim veren bir mekân olmalarının yanı sıra velilerin de sosyalleştiği birer toplanma alanıdır.

- Çocuğunun Türkçe öğrenmesi için başvuran velilerin sonraki süreçler (dersin niteliği, öğrencinin takip edilmesi, öğretmen ile iş birliği yapılması vb.) için yaklaşımları değişkenlik göstermektedir (N10).

Örnekler:

ilgisiz veliler de vardır mutlaka ama daha çok öğrencilerin durumu ile ilgilenen ve öğretmene kıymet veren okul yönetimi ve velilerle bir arada oldum herhalde ben şanslıydım (Ö4, Ö5, Ö9).

Velinin backgroundu, geldiği sosyal yapı, sosyal çevre çok önemli ve maalesef veliler açısından pek olumlu şeyler söyleyemeyeceğim. Çocukların hazırbulunuşluk düzeyini de etkiliyorlar (Ö1).

Veliler konusuna gelince maalesef veliler bizim kanayan yaramız. Türkiye'deki ikinci yazlığını, ikinci dairesini almak, arabasını büyütmek. Böyle olunca da çocuk Türkçe biliyorsa, Türkçe konusu onun için yeterlidir, daha fazla şey yapmak istemiyor. Burada veliler çok da bilinçli değil (Ö3). 
Velilerle biraz sizin şansınıza kalmış, nasıl bir veliyle karşılaşacağınız ama şöyle bariz bir fark var; şu anda online eğitimde yazışıyorum ya da oradaki velilerim gerçekten profil çok farklı, biraz daha böyle eğitimli insanlar (Ö5).

- Çocukları ulusal sınavlara Türkçe hazırlanan veliler, Türkçe ve Türk Kültürü dersine diğer velilerden daha ilgilidir.

Örnekler:

Bunun dışında veliler çocuğunu sınava hazırlıyorsa çok ciddiye alıyor GCSE ya da A level ise çok ciddiye alıyor, dersi değilse çok fazla ciddiye almayabilir. Camiler yine arkadaşların belirttiği gibi camideki din eğitimi için geldiğinde sizi çok ciddiye almıyor yine böyle bir klişe var (Ö7).

Bazı veliler de sadece çocuğunu hani orada çocuklarım burada dursun birkaç saat ben işimi halledeyim geleyim ondan sonra bir şekilde burada otursunlar yaklaşımı da var. Bazıları sadece kendi arsında sosyalleşmeye geliyorlar aslında bu da güzel bir şey toplum olarak bizler öğretmenler olarak ne kadar birbirimizle buluşamıyorsak insanlar da gündelik hayatında birbirleriyle buluşamıyorlar (Ö2).

İngiltere'de yaşayan Türkler, çocuklarının Türkçe öğrenmesini istemektedir. Bunun için Türkiye'nin T.C. Londra Eğitim Müşavirliğine başvurarak Türkçe ve Türk Kültürü öğretmeni istemektedir. Ancak çoğu veli bu istekten sonra öğrencinin durumu ile çok ilgilenmemektedir. Daha çok kendi gündelik işleri ile meşgul olmakta, çocuklarının gelişimini takip etmemektedirler. Fakat ulusal sınavlar için Türkçe dersini saydırmak isteyen öğrenciler ve onların velileri Türkçe ve Türk Kültürü dersini ciddiye almaktadır. Bunlar üniversiteye girişte yüksek bir puan alabilmek için çaba göstermekte ve Türkçeyi iyi öğrenmeye odaklanmaktadır.

\section{Tartışma ve Sonuç}

Ingiltere'de yaşayan Türkler, kendi kültürlerini devam ettirebilmek, dillerinin unutulmasını engellemek veya çocuklarının daha iyi bir üniversite eğitimi almalarını sağlamak için Türkçe ve Türk Kültürü dersine ilgi duymaktadır. Bu sebeple gönüllü iştiraklerle kurdukları Türk dernekleri veya var olan sivil toplum kuruluşları aracılı̆ıyla T.C. Londra Eğitim Müşavirliğine ya da KKTC Eğitim ve Kültür Ataşeliğine başvurarak çocuklarının başta Türkçe ve Türk Kültürü dersleri olmak üzere müzikten resme kadar kültürel değerleri edinmelerini istemektedir.

Türkçe ve Türk Kültürü dersi İngiltere'de üç farklı ortamda verilmektedir: cami dernekleri, ingiliz okulları ve belediyeler bünyesindeki halk eğitim merkezleri. Bu ortamlarla ilgili elde edilen bulgulara göre;

- En elverişli eğitim yeri İngiliz okullarıdır.

- Cami dernek okulları birer ibadethane olarak inşa edildiğinden birçoğu eğitim-öğretim için yeterli şartlara sahip değildir. Camilerde, sınıf düzeni mevcut olmadığı gibi eğitim ya çok küçük odalarda ya da cami cemaatinin kullandığı ibadet alanlarında yapılmaktadır. Çok az camide müstakil sınıflar mevcuttur.

- Halk eğitim merkezi niteliğindeki binalar, eğitim açısından cami ortamlarından daha elverişlidir. Ancak İngiliz okulları kadar iyi şartlara sahip değildir.

İngiltere'deki Türkçe eğitimi ile ilgili Betül Yıldııım'ın 2016 yılında yayımladığı çalışmada öne sürülen bazı iddialar ile burada elde edilen sonuçlar örtüşmemektedir. Yıldırım'a göre çok az sayıda İngiliz devlet okulunda Türkçe eğitimi yapılmaktadır. Ancak bu araştırmaya göre söz konusu okulların sayısı 49'dur. Velilerin istemesi durumunda bu sayının artması da mümkündür. Ayrıca velilerin önemli bir kısmı okullara değil, dernek veya vakıflara başvurarak çocuklarına Türkçe ve Türk Kültürü dersini aldırabilmektedir.

Ingiltere'de Türkçe ve Türk Kültürü dersleri Türklerin yoğun yaşadığı Londra'nın yanı sıra Edinburg, Hull, Portsmouth, New Port, Swindon, Luton, Bristol, Coventry, Norhampton, Manchester, Brighton, Canterbury, Kent, Leicester, New Castle, Notthingham, Reading şehirlerinde de verilmektedir. Türkler, Londra'nın kuzeyinde yoğun bulunsa da Türkçe ve Türk Kültürü dersleri, oluşan talebe uygun olarak şehrin farklı noktalarında okutulmaktadır. Bunun yanında Türk okullarııın dağılımının Türk nüfusunun dağılımına paralellik gösterdiği söylenebilir. Bu okulların çoğu Türklerin sayıca çok oldukları Kuzey Londra'da yer almaktadır. Bayat (2016: 154) dağınık haldeki Türk okullarını birleştirmek ya da şehrin farklı bölgelerinde kurulacak müstakil okullarla bu dersin daha verimli 
işlenmesinin sağlanabileceğini söylemektedir. Ancak bunun önünde çeşitli mali ve idari problemler vardır. Örneğin İngiltere' deki Türk dernek okulları, okul derslikleri ya da halk eğitim merkezi kiralarken ekonomik ve bürokratik sorunlar yaşamaktadır. Bu sorunlar, Türkçe ve Türk Kültürü derslerinin verildiği diğer Avrupa ülkeleri için de geçerlidir. Nitekim Yıldız (2012: 263) Almanya özelinde yaptığı araştırmada Türkçe ve Türk Kültürü dersi için sınıf tahsisi, kira, elektrik, sigorta gibi engellerin kaldırılması gerektiğini ifade etmektedir. Yine Türkiye Maarif Vakfı́nın Londra'da müstakil okul binası açma yönündeki girişimleri Londra'daki binaların pahalı olması yüzünden şimdilik sonuçsuz kalmıştır.

İngiltere'deki Türkçe ve Türk Kültürü dersi için T.C. Millî Eğitim Bakanlığı 2019-2020 eğitimöğretim yılı için 3114 Türkçe ve Türk Kültürü ders kitabı göndermiştir. Bu kitaplar Hazırlık 1-2 ve 8 farklı seviye için hazırlanmış kitaplardır. Ancak küresel salgının yarattığı şartlar ve derslerin genellikle çevrim içi yapılıyor olması nedeniyle MEB, 2020-2021 yılı için Ingiltere'ye ve diğer yurt dışı temsilcciliklerine kitap göndermemiştir. İngiltere'de görevli öğretmenler çoğu zaman kendi materyallerini kendileri hazırlamaktadır. Bu da eğitimde bireysel farklılıkları ve öğretmenlik yeteneklerini ön plana ortaya çıkarmaktadır. Ayrıca eğitim ortamları temel materyallere (tahta, fotokopi, yansıtıcı vb.) erişim konusunda da belirleyici olabilmektedir. Bu konuda İngiltere'deki eğitimin genel görünümü şöyledir:

- Türk dernek okullarında, temel ders araç gereçleri konusunda bazen sıkıntılar yaşanabilmektedir.

- İngiliz okullarında ders saatlerinden sonra yapılan kulüp etkinliği biçimindeki Türkçe ve Türk Kültürü dersleri sınıf ortamında gerçekleştiğinden temel materyallere erişim açısından sıkıntı yaşanmamaktadır. Ancak bazı okul yönetimleri söz konusu materyallerin kullanımını engelleyebilmektedir.

- Ders kitapları sistematik bir eğitim imkânı sunduğu için faydalıdır. Ancak İngiltere özeline hazırlanmadığı için içerik açısından eksiktir. Yine bu kitaplar görsel açından güzel olsalar da bazı teknik sorunlar içermektedir. Örneğin ders kitaplarındaki bazı karekodlar çalışmamaktadır. Millî Eğitim Bakanlığı, Türkçe ve Türk Kültürü dersleri için ders kitaplarının yanı sıra çeşitli materyallerin kullanılmasını da gündemine almıştır. Bunun için yurt dışındaki Türk çocuklarına hitap eden etkileşimli hikâye kitapları hazırlanmış ve bu kitaplar Eğitim Bilişim Ağı (EBA) üzerinden hizmete sunulmuştur. EBA yurt dışı modülünün ders kitapları ve ders içerikleri ile daha da zenginleştirilmesi gerekmektedir. 2011 yılında yapılan İngiltere Türk Toplumu Eğitim Çalıştayı sonuç bildirisinde Türk çocuklarının eğitim hayatlarında çok önemli bir yere sahip olan GCSE ve A Level Turkish dersleri için kitaplar hazırlanması, bu kitaplarda dört temel dil becerisini ölçen görsel ve işitsel araçların kullanılması gerektiği ifade edilmiştir. Geçen süre zarfında GCSE ve A Level Turkish için kitaplar hazırlanmamış ve bu derslerin hazırlıkları öğretmenlerin maharetine bırakılmıştır. Bu sınavlara hazırlık süreçleri öğrencilerin Türkçe ve Türk Kültürü dersine ilgilerini etkilemektedir. Öğrencilerin lise mezunu sayılabilmek ve üniversiteye yerleşebilmek için seçtikleri derslerden başarılı olmaları gerekmektedir. Türk öğrenciler, Türkçe GCSE sınavına girerek bu derslerden birini yüksek bir notla geçebilmektedir. Üniversite giriş sınavlarında 3 dersten başarılı olmak zorunda olan Türk öğrenciler, A Level Turkish sınavından başarılı olarak bunlardan birini aşmaktadır. Yıldırım (2016), GCSE ve A Level Turkish sınavlarının 2019 yılında kalkacağını iddia etmiş olsa da bu sınavların 2020-2021 yılı itibarıyla devam ettiği ve şu aşamada yürürlükten kaldırılmasının söz konusu değildir. Türkçe $A$ Level pek çok üniversite tarafından kabul edilmektedir.

Öğrenciler, genellikle velilerinin isteği ile Türkçe ve Türk Kültürü dersine katılmaktadır. Uysal (2015) Londra'da okul çağında olan Türk çocuklarının sayısının 30 bin civarında olduğunu söylemektedir. Türk okullarına devam eden öğrenci sayısının 2541 olduğu düşünüldüğünde Türkçe ve Türk Kültürü derslerinin ulaştığı öğrenci sayısının ne kadar az olduğu açıkça görülebilir. Bunun için Türkçe ve Türk Kültürü dersine katılımı teşvik edici uygulamaların geliştirilmesi gerekmektedir. Derse katılan öğrencilerin kimisi bu dersleri severek takip ederken kimisi ortama kerhen devam etmektedir. Ancak velilerin ve özellikle öğretmenlerin uyguladığı yöntem ve teknikler bu tutumların olumluya dönmesinde belirleyici olmaktadır. Bu da Türkçe ve Türk Kültürü dersinde öğretmen çabasının, farklı yöntem ve teknikleri denenmesinin önemini ortaya koymaktadır. Bu yüzden Türkçe ve Türkçe Kültürü dersine Türkçe Eğitimi, Türk Dili ve Edebiyatı veya İngilizce Eğitimi gibi dil öğretiminde tecrübe sahibi 
kişilerin görevlendirilmesi daha yararlı olacaktır. Zira ana dili eğitiminin farklı teknik ve yöntemlerini bilen ve uygulan öğretmenler, bu ortama daha hızlı uyum sağlayabilirler.

Türkçe ve Türk Kültürü dersine katılan öğrenci grupları homojen değildir. Türkiye'deki birleştirilmiş sınıf düzeninde bir yapıları vardır. Bir grubun içinde farklı yaşlarda ve değişik Türkçe bilgi seviyelerine sahip kişiler bulunmaktadır. Bu da öğretmenlerin bir müfredat takip etmesini, sınıfta tam öğrenme gerçekleştirmesini ya da bir etkinliğe tüm sınıfı katmasını güçleştirmektedir. Öğrencilerin dile yaklaşımları da öğrenmeyi etkileyen faktörlerdedir. Okur (2015) yaptığı çalışmada, Londra'da evlerinde Türkçe konuşan çocukların Türkçeyi kolay bir dil olarak algıladıklarını ifade etmiştir. Bircan ve Güler (2020: 18), Londra'da iki dilli çocukların dil tercihlerine dair yaptıkları çalışmada Londra'da doğup büyüyen Türk çocuklarının sadece yarısının her zaman ailesiyle Türkçe konuşmaktan hoşlandığını ve çok az bir kısmının ise hiçbir zaman bundan hoşlanmadığını tespit etmişlerdir. Aynı çalışmada Londra'daki Türk çocuklarının çoğunluğunun ailelerinin kendileriyle ingilizce konuşmasından her zaman daha mutlu oldukları ortaya konulmuştur. Her iki bulgu da Türk çocuklarının çoğunluğunun aileleriyle iletişim kurarken İngilizce ile kendilerini daha iyi ifade edebildiklerini göstermektedir. Özdemir (2016), İskoçya'da yaşayan birinci ve ikinci kuşak Türklerin dil tercihlerini incelediği çalışmasında İskoç okullarına giden ikinci kuşağın İngilizceyi öncelikli dil olarak tercih ettiğini belgelemiştir. Yıldız (2013) da Almanya'daki farklı bölgelerde öğrenim gören 11-18 yaş grubundaki Türk öğrencilerine yönelik yaptığı çalışmasında öğrencilerin aileleriyle ve Türk arkadaşlarıyla iletişim kurmak için Türkçe öğrenmek istediklerini belirlemiştir. Belet'in (2009) Norveç'te yaşayan Türk çocuklarına yönelik yaptığı çalışmanın bulguları, Yıldız'ın (2013) çalışmasındaki bulguları desteklemektedir. Bu çalışmada Türk çocuklarının Türkçe öğrenme amacının aileleri ile iyi iletişim kurmak olduğu ortaya çıkmıştır. Verhoeven (1996), Hollanda'nın büyük kentlerinde yaşayan Türklere yönelik yaptığı çalışmada çocukların aileleriyle Türkçe konuştuklarını belirtmiştir. İngiltere'de çocuklar kardeşleriyle İngilizce konuşurken ebeveynleri ile çoğunlukla Türkçe konuşmaktadır. Ancak İngilizce konuşmayı daha çok sevmektedir.

İngiltere'de Türkçe ve Türk Kültürü dersine katılan öğrencilerin Türkçe bilgisini ölçecek bir sınav sistemi bulunmamaktadır. Sınıftaki öğrencilerin seviyesine, hangi kitabı kullanacaklarına, hedef öğrenmelerine öğretmenler ve okul yönetimi karar vermektedir. Öğrencilerin gelişim seviyesinin ölçülmesi ve onlara dönüt verilerek ilerlemelerinin sağlanması gerekmektedir. 2020-2021 yılında uygulamaya konulan ve okuma ile dinleme becerilerini ölçmeyi hedefleyen Kazanım Değerlendirme Sınavı (KDS) bu yönde atılmış olumlu bir adımdır. Bu sınavın olgunlaştırılarak diğer ülkelerde Türkçe ve Türk Kültürü dersini alan öğrencilere uygulanması öğrencilerin motivasyonunu arttıracaktır.

Ingiltere'de Türkçe ve Türk Kültürü dersi için görevlendirilmiş öğretmenler her sene başında Londra Eğitim Müşaviri tarafından farklı okullara görevlendirilmektedir. Öğrenciler bu durumu bildiklerinden bazen olumsuz tutumlar geliştirmektedir. Yine öğretmenler açısından çok farklı okullara gitmek bazen taşınmayı bazen de uzun tren yolculukları yapmayı gerekli kılmaktadır.

Ingiltere'ye ilk kez atanan öğretmenler, daha önce burada bulunan öğretmenler tarafından karşılanmakta ve desteklenmektedir. Daha sonra farklı bölge ve okullarda çalışmalara başlansa da öğretmenler arasındaki iletişim ve iş birliği devam etmektedir. Ancak bu öğretmenlerin özellikle ekonomik sıkıntıları mevcuttur. Aldıkları ücret Londra'daki hayat pahalılığı karşısında öğretmenleri zor durumda bırakmaktadır. Aylıklar, normal bir mahalledeki 1+1 ev kirası kadardır veya daha azdır. Bu yüzden öğretmenler ev kiralamak yerine oda kiralamakta ya da Londra dışındaki şehirlerde yaşamak istememektedir. Çünkü bu şehirler Londra'ya oranla daha ucuzdur.

Çocuğunun Türkçe öğrenmesi için başvuran velilerin sonraki süreçler (dersin niteliği, öğrencinin takip edilmesi, öğretmen ile iş birliği yapılması vb.) için yaklaşımları değişkenlik göstermektedir. Yaman ve Dağtaş (2015) çalışmalarında İngiltere'de yaşayan Türk ailelerin birçoğunun Türkçeye karşı olumsuz tutum içinde olduklarını belirtmişlerdir. Aynı çalışmada, İngiltere'deki iki dilli Türk çocuklarına Türkçe öğreten öğretmenlerin ihtiyaç analizi yapılmıştır. Bu analize göre öğretmenlerin yarısından fazlası, İngiltere' deki Türk aileleri ve çocuklardan kaynaklanan eksiklikleri önemli bir sorun olarak görmektedir. Türk aileleri ve çocukların birçoğu, Türkçe ve Türk Kültürü derslerinin tam anlamıyla gerçekleştirilebilmesi için kendilerine düşen görev ve sorumluluklardan kaçınmaktadır. Velilerin ana dili eğitimi konusunda yeterli bilince sahip olmadığı çeşitli çalışmalarda (Belet, 2009; Güler, 2015; Yağmur, 
2011; Yıldırım, 2016; Yıldız, 2012) ifade edilmiştir. Velilerin tutumları öğrencilerin derse karşı tutumlarını da büyük oranda etkilemektedir. İlgili velilerin çocukları derse daha yoğun katılım gösterirken diğer velilerin öğrencileri daha az ilgi göstermektedir. Çocukları ulusal sınavlara Türkçeden hazırlanan veliler, Türkçe ve Türk Kültürü dersine diğer velilerden daha ilgilidir.

\section{Öneriler}

Türk nüfusunun yoğun olduğu Kuzey Londra gibi bölgelerde Türkiye'nin okul binalarına yatırım yapması ve Bayat'ın (2016: 154) da belirttiği gibi dağınık haldeki Türk okullarını birleştirecek müstakil eğitim binalarının inşa edilmelidir. Türkiye Cumhuriyeti bu konuda gerekli mali ve siyasi desteği sağlamalıdır.

İngiltere'deki Türkçe ve Türk Kültürü dersi için T.C. Millî Eğitim Bakanlığı 2019-2020 eğitimöğretim yılı için Türkçe ve Türk Kültürü ders kitabı göndermiştir. Bu kitapların her sene gönderilmelidir. Ayrıca söz konusu kitaplar her ülkenin pedagojik, sosyal, siyasi ve kültürel durumuna uygun içeriklerle donanmalıdır.

Ders kitaplarındaki bazı karekodlar çalışmamaktadır. Millî Eğitim Bakanlığı, Türkçe ve Türk Kültürü ders kitaplarını göndermeden önce sıkı bir denetimden geçirmeli ve kaynakların kalitesini yükseltmelidir.

Özellikle Türk dernek okullarında temel ders araç gereçleri konusunda bazen sıkıntılar yaşanabilmektedir. Hem bu sıkıntıların giderilmesi hem de öğrencilerin Türkçe ve Türk Kültürü dersine teşvik edilmesi için çalışmalar yapılmalıdır.

Ingiliz okullarında bazı okul yönetimleri okula ait materyallerin kullanımını engelleyebilmektedir. Bunların önüne geçmek için İngiltere'de Türkiye ve Türkçe lehine faaliyetlerin sayısı arttırılmalı, olumlu bir kamuoyu oluşturulmalıdır.

GCSE ve A Level Turkish sınavları öğrencileri Türkçe ve Türk Kültürüne ısındırmakta, ilgilerini arttırmaktadır. Ancak bu sınavlara yönelik herhangi bir kaynak bulunmamaktadır. Bu sınavlarla ilgili kaynaklar ivedilikle hazırlanmalıdır.

Türkçe ve Türk Kültürü dersini alabilecek öğrencilerin büyük bir kısmı bu ders için başvuru yapmamaktadır. Bu dersi ilgi çekici kılmalı, hitap edilen kitleye ulaşmalı ve gerekli tanıtımlar yapılmalıdır.

İngiltere'de Türkçe ve Türk Kültürü dersine katılan öğrencilerin homojen sınıflarda eğitim alabilmesi için eğitim-öğretim döneminin başında seviye belirleme sınavları yapılmalıdır. Türkçe bilgisi farklı olan öğrenciler aynı ortamda ders almamalıdır.

İngiltere'de Türkçe ve Türk Kültürü dersi için görevlendirilmiş uzmanlığı Türkçe veya Türk Dili ve Edebiyatı olmayan öğretmenler, uyum semineri dışında bir hizmet içi eğitime tabi tutulmalı ve alan bilgileri zenginleştirilmelidir.

Türkçe ve Türk Kültürü dersi alan öğrenci velilerinin okula ve derse ilgilerini arttıracak etkinlikler düzenlenmelidir.

Türkçe ve Türk Kültürü dersi öğretmenlerinin İngiltere'deki sosyal ve ekonomik şartları iyileştirilmelidir.

\section{Araştırma ve Yayın Etiği}

Bu çalışmada "Yükseköğretim Kurumları Bilimsel Araştırma ve Yayın Etiği Yönergesi" kapsamında uyulması belirtilen tüm kurallara uyulmuştur. Yönergenin ikinci bölümü olan "Bilimsel Araştırma ve Yayın Etiğine Aykırı Eylemler" başlığı altında belirtilen eylemlerden hiçbiri gerçekleştirilmemiştir. (Zorunlu beyan)

Bu araştırma için hem T.C. Londra Eğitim Müşavirliğinden izin hem de Tokat Gaziosmanpaşa Üniversitesi Sosyal ve Beşerî Bilimler Araştırmaları Etik Kurulu'ndan rapor alınmıştır.

\section{Araştırma izni}

Kurul adı= T.C. Londra Eğitim Müşavirliği

Karar tarihi $=01.01 .2021$

Belge sayı numarası $=134$ 


\section{Etik Kurul Izni}

Kurulu

Kurul adı= Tokat Gaziosmanpaşa Üniversitesi, Sosyal ve Beşeri Bilimler Araştırmaları Etik

Karar tarihi $=12.02 .2021$

Belge sayı numarası $=12166$

\section{Yazarların Katkı Oranı}

Bu çalışmaya 1. yazar \%50, 2. yazar da \%50 oranında katkı sağlamıştır.

\section{Çıkar Çatışması}

Bu çalışmada çıkar çatışması teşkil edebilecek herhangi bir durum yoktur.

\section{Destek ve Teşekkür}

Ingiltere'deki Türkçe ve Türk Kültürü dersleri ile ilgili bu çalışmanın hazırlanmasına onay veren T.C. Londra Eğitim Müşavirliğine, çalışmaya katılan Türkçe ve Türk Kültürü öğretmenlerine desteklerinden dolayı teşekkür ederiz.

\section{Kaynaklar}

Bayat, A. (2016). iki dillilik bağlamında ingiltere'de yaşayan Türk çocuklarının ana dili Türkçeyi öğrenme durumları (Yayımlanmamış yüksek lisans tezi). Gazi Üniversitesi Eğitim Bilimleri Enstitüsü, Ankara.

Belet, Ş. D. (2009). i̇ki dilli Türk öğrencilerin ana dili Türkçeyi öğrenme durumlarına ilişkin öğrenci, veli ve öğretmen görüşleri (Fjell ilköğretim okulu örneği, Norveç). Selçuk Üniversitesi Sosyal Bilimler Enstitüsü Dergisi, 21, 71-85.

Çalışkan, N. ve Toyran, M (2018). Türkçe ve Türk kültürü ders materyalleri. İngiltere: Yurtdışı Türkler ve Akraba Topluluklar Başkanlığı.

Çokluk, Ö., Yılmaz, K. ve Oğuz, E. (2011). Nitel bir görüşme yöntemi: odak grup görüşmesi. Kuramsal Eğitimbilim, 4(1), 95-107.

Demir, M. (2016). İngiltere'de Türk olmak. Erişim Adresi: https://www.hotcourses-turkey.com/studyin-the-uk/destination-guides/living-in-the-uk/

Elmusharaf, K. (2016). Qualitative sampling techniques. Erişim Adresi: https://www.gfmer.ch/SRHCourse-2016/research-methodology/pdf/Qualitative-sampling-techniques-Elmusharaf2016.pdf

Eyüp, B. ve Güler, E. B. (2020). íki dilli Türk çocukların dil tercihlerinin sebepleri: Londra örneği. Ankara Bilim Researcher, 8(3), 1-24.

ICEPWORLD (2017). İngiltere'de Türk toplumu. Erişim Adresi: https://www.icep.com.tr/ulkelerrehberi/ingiltere-rehberi/ingiltere-de-turk-toplumu

Ingiltere Türk Toplumu Eğitim Çalıştayı (2011). Kararlar. Londra.

Kaya, i. (2008). Avrupalı Türkler: Misafir işçilikten Avrupa vatandaşığına, Doğu Coğrafya Dergisi, 19, 149-169.

KKTC Dışişleri Bakanlığı (2021). Yurt dışında yaşayan Kıbrıslı Türkler. Erişim Adresi: https://mfa.gov.ct.tr/tr/dis-politika/yurt-disinda-yasayan-kibrisli-turkler/

Kuzu, A. (2013). Araştırmaların planlanması. A. A. Kurt (Ed.), Bilimsel araştırma yöntemleri içinde (s. 1946). Eskişehir: T.C. Eskişehir Anadolu Üniversitesi Yayını.

Mapping London (2013). Second languages. Erişim Adresi: https://mappinglondon.co.uk/2013/second-languages/

Okur, A. (2015). Language use of Turkish speaking communities in the United Kingdom (A case study according to the views of families, teachers, and students). International Online Journal of Educational Sciences, 6(12), 292-306.

Özdemir, S. (2016). İskoçya' da yaşayan Türklerin dil kullanımları ve dil tercihlerinde bireysel etmenler. Turkish Studies, 11(4), 761-782. 
Şahsuvaroğlu, T. ve Ekşi, H. (2008). Odak grup görüşmeleri ve sosyal temsiller kuramı. Marmara Üniversitesi Atatürk Eğitim Fakültesi Eğitim Bilimleri Dergisi, 28(1), 127-139.

Şimşek, A. (2012). Araştırma modelleri. A. Şimşek (Ed.), Sosyal bilimlerde araştırma yöntemleri içinde (s. 80-106). Eskişehir: T.C. Eskişehir Anadolu Üniversitesi Yayını.

T.C. Dışişleri Bakanlığı (2021). Yurt dışında yaşayan Türk vatandaşları. Erişim Adresi: https://www.mfa.gov.tr/yurtdisinda-yasayan-turkler_.tr.mfa

Tekindal, M. ve Uğuz Arsu, Ş. (2020). Nitel araştırma yöntemi olarak fenomenolojik yaklaşımın kapsamı ve sürecine yönelik bir derleme. Ufkun Ötesi Bilim Dergisi, 20(1), 153-182.

MEB (2019). Türkçe öğretim programı. Erişim Adresi: https://mufredat.meb.gov.tr/

MEB (2018). Türkçe ve Türk kültürü öğretim programı. Erişim Adresi: http://abdigm.meb.gov.tr/

Uysal, A. (2015). Bir diaspora mekânı olarak Londra Türk okulları. Uluslararası Sosyal Araştırmalar Dergisi, 8(41), 756-768.

Uysal, A. (2016a). Londra'daki Türk nüfusunun mekânsal dağılımı. Marmara Coğrafya Dergisi, 33, 534565.

Uysal, A. (2016b). Londra'daki Türklere ait toplumsal ve kültürel organizasyonlar, Uluslararası Sosyal Araştırmalar Dergisi, 9(47), 429-440.

Verhoeven, L. (1996). Turkish literacy and its acquisition in the Netherlands. International Journal of the Sociology of Language, 119, 87-108.

Wikipedia (2021). Birleşik Krallık'taki Türkler. Erişim Adresi: https://tr.wikipedia.org/wiki/Birle\%C5\%9Fik_Krall\%C4\%B1k\%27taki_T\%C3\%BCrkler

Yağmur, K. (2007). iki dilli çocukların dil becerilerinin ölçümü ve eşik kuramı. Dil Dergisi, 135, 60-76.

Yaman, H. ve Dağtaş, A. (2015). İngiltere'deki iki dilli Türkçe çocuklarına Türkçe öğreten öğretmenlerin ihtiyaç analizi: Swot analiz örneği. Uluslararası Sosyal ve Eğitim Bilimleri Dergisi, 2(4), 47-82.

Yıldırım, B. (2016). İngiltere'deki Türkler ve Türkçe eğitimi üzerine bir çalışma, Uluslararası Türkoloji Araştırmaları ve incelemeleri Dergisi, 1, 15-23.

Yıldız, C. (2012). Yurt dışında yaşayan Türk çocuklarına Türkçe öğretimi (Almanya örneği). Ankara: Yurt Dışı Türkler ve Akraba Topluluklar Başkanlığı.

Yıldız, C. (2013). Almanya'da ana dili olarak Türkçe öğretimine ilişkin öğrenci görüşleri. Adıyaman Üniversitesi Sosyal Bilimler Enstitüsü Dergisi-Türkçenin Eğitimi Öğretimi Özel Sayısı, 6(11), 1083-1113.

\section{Introduction}

\section{Extended Abstract}

Turkish is one of the 10 most spoken languages in the UK. Turkish children who continue their education in British schools on weekdays can attend Turkish schools in the evenings or on weekends. However, these schools are distinctly different from conventional schools. Bayat (2016) named these schools as centers. In those schools, the Turkish and Turkish Culture course is taught. Therefore, these schools function like courses. The teachers are either appointed by the Republic of Turkey or TRNC volunteers, and the burden of teaching Turkish as the mother tongue is mostly on the London Turkish Embassy Office of the Education Counsellor in terms of both personnel and training material.

Starting in the 2020-2021 academic year, 5 Turkish teachers, 7 Turkish Language and Literature teachers, 9 Elementary school teachers, 8 English teachers, 4 Religious Culture and Morals teachers, 2 Accounting Teachers, 1 Social Studies Teacher, 1 Mathematics Teacher, and 1 Counsellor are working. As seen, the Ministry of National Education does not distinguish between subject areas when assigning teachers to teach the Turkish and Turkish Culture courses.

In the course, teachers or students change constantly. The number of students may range from 3 to 20 in classes. There may also be differences in terms of both age and proficiency level among these students. Students' age may be between 5 and 18, and their Turkish proficiency level can be between 1-8. These students can prepare for the exams called GCSE Turkish and A-Level Turkish after the 8th grade. Students' proficiency levels are determined based on the observations and evaluations of the school administrations and teachers. While the course materials are prepared by the Ministry of National Education and distributed according to the students' levels, learning methods and techniques 
are up to the teachers' skills. As of 2021, mother tongue courses in Turkish continue in 45 British schools, most of which are in London, and 49 Turkish association schools.

\section{Method}

This research is designed as phenomenological research. this method, a complex situation can be studied longitudinally by defining broadly and determining its components in its natural environment (Subaşı and Okumuş, 2017: 425). The data were collected from a focus group study with teachers. The teachers who participated in the study were determined through the purposeful sampling method. During the focus group meeting, the opinions of the participants were obtained on the following issues:

1. Educational environments and their effects on education

2. Turkish and Turkish Culture coursebooks and material usage

3. Students' attitudes towards the Turkish and Turkish Culture course

4. teachers and their influence on the Turkish and Turkish Culture course

5. Parents' approach to the Turkish and Turkish Culture course

\section{Results and Discussion}

Turkish and Turkish Culture lesson is offered in three different settings in the UK: mosques, British schools, and public education centers of municipalities. The analysis showed that

- The most convenient place of study was English schools.

- As mosques are built as places of worship, they did not offer an environment conducive to learning. There were classrooms only in very few mosques.

- Public education centers were more suitable for education than mosques. However, British schools offered better learning environments than those centers.

The analysis showed that the course was taught in London more than any other location in the UK. Bayat (2016: 154) states that the course can be taught more effectively by combining Turkish schools that are scattered across the city or through independent schools to be established in different parts of the city.

The data revealed that teachers often prepared their materials which reflected individual differences and skills of the teachers. Educational contexts were also decisive for access to basic materials such as boards, photocopying facilities, projectors, etc.) The general view of education in the UK on this subject is as follows:

- In Turkish schools, there were sometimes problems with basic course materials.

- The Turkish and Turkish Culture classes were taught during after-school hours in English schools. They were taught in classroom environments. However, some school administrations prevented the use of classroom facilities.

- Students usually attended the course at the request of their parents. Uysal (2015) states that the number of Turkish children at school age in London is around 30 thousand. However, at the time of the study, the number of students attending Turkish schools was 2541 . This is a very low number.

-The students' attitudes towards the course varied as well. While some attended the classes enthusiastically, others were reluctant. However, parents and especially teachers were instrumental in turning those attitudes into positive.

- The student groups were not homogeneous in terms of proficiency. This made it difficult for teachers to follow the curriculum or involve the entire class in activities. Students' attitudes towards language also affected their learning.

-There is no exam system to measure students' Turkish knowledge. It is necessary to measure the extent of student learning and ensure progress through feedback. The Outcome Assessment Exam (KDS), which began to be used in the 2020-2021 school year aims to measure the students' reading and listening skills, and it is a positive step in this direction. However, the exam results are not announced, and the exam does not measure writing and speaking skills.

-The attitudes of parents vary as well. Yaman and Dağtaş (2015) found that many Turkish families living in England had a negative attitude towards Turkish. Many Turkish families do not live 
Yurt Dışında Yaşayan Türkler ve Türkçe Eğitimi: İngiltere Örneği (Genel Durum, Sorunlar ve Öneriler)

their culture and language in their homes. This causes an obstacle for students. In addition, some parents do not have awareness of the importance of mother tongue education (Yağmur, 2011; Yıldız, 2012; Belet, 2009; Güler, 2015). Unlike those parents, families that encourage their children to prepare for the national exams in Turkish are more interested in the Turkish and Turkish Culture course. 